\title{
$Q E$
}

945

.18

M36

1854

(5)

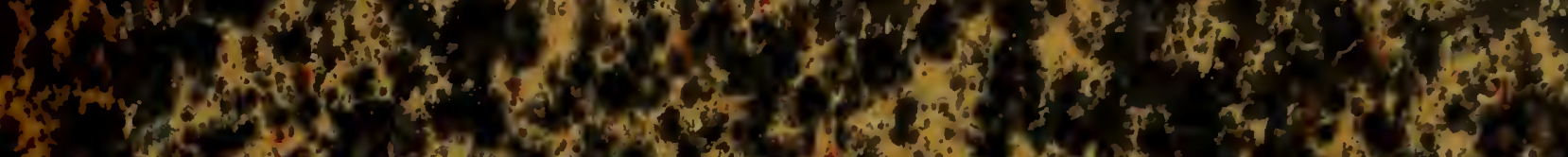

ors

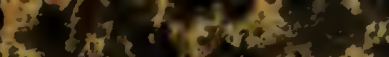

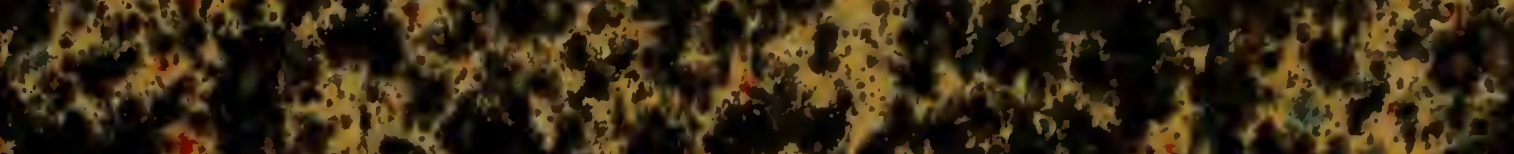

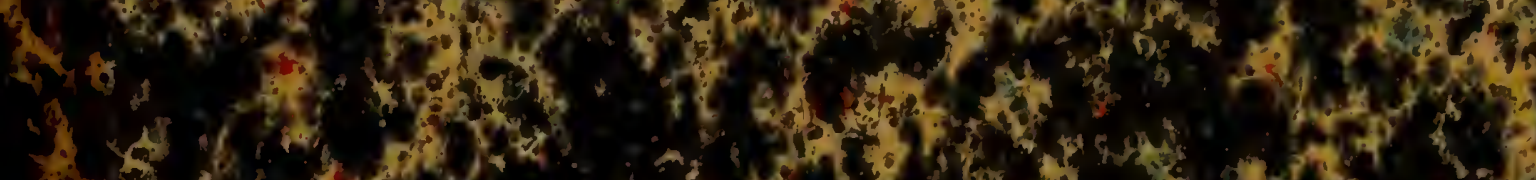

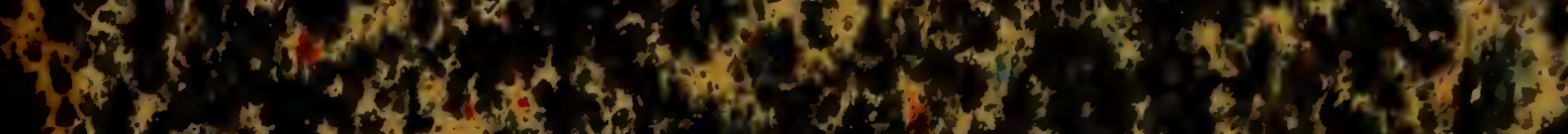

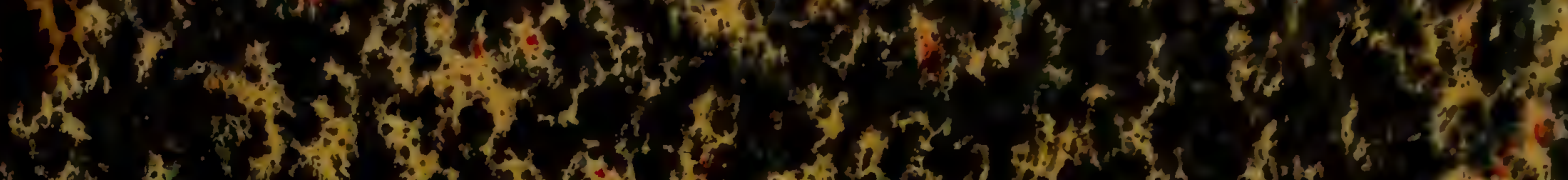
(1) 5. If 1.

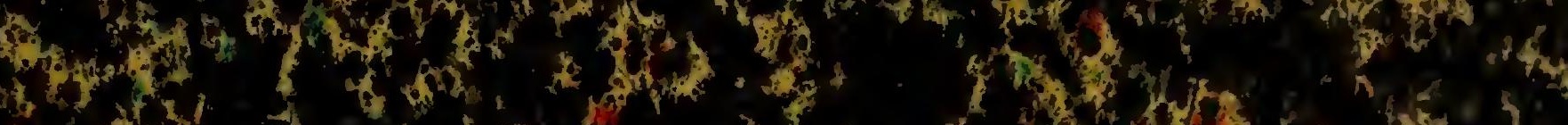

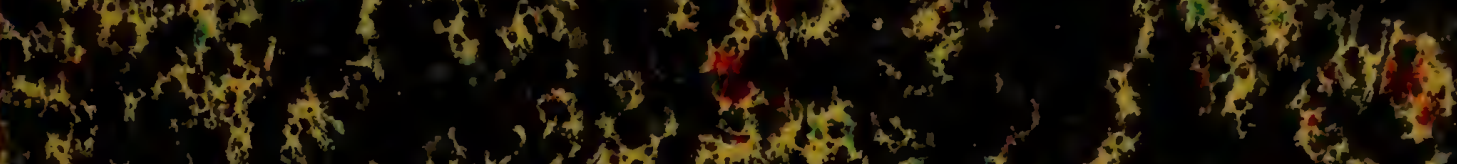

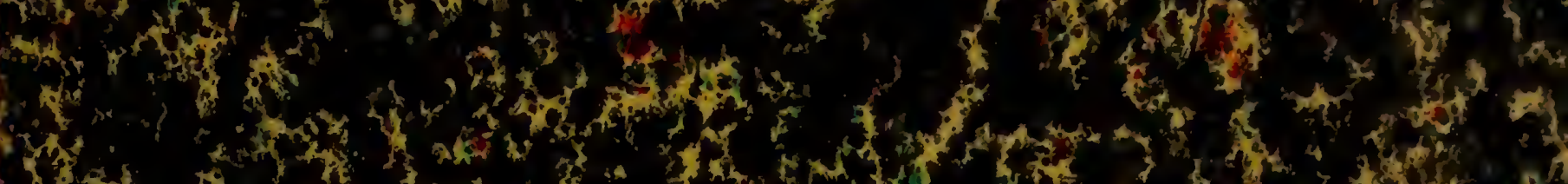
1.1.

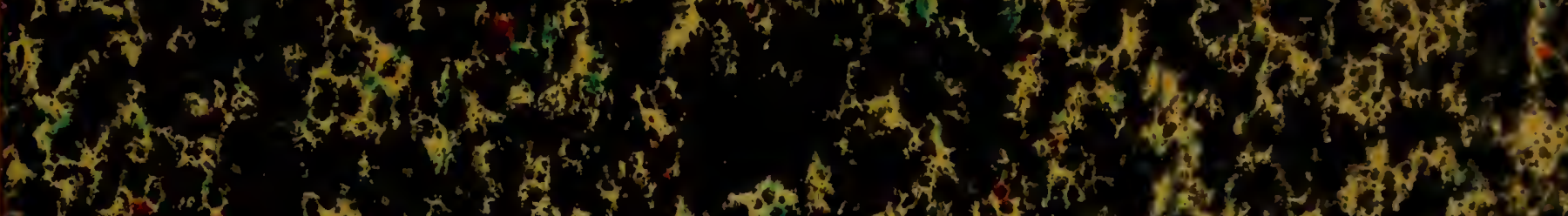

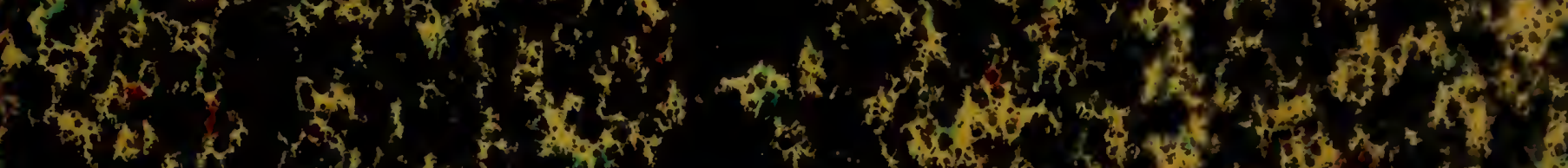

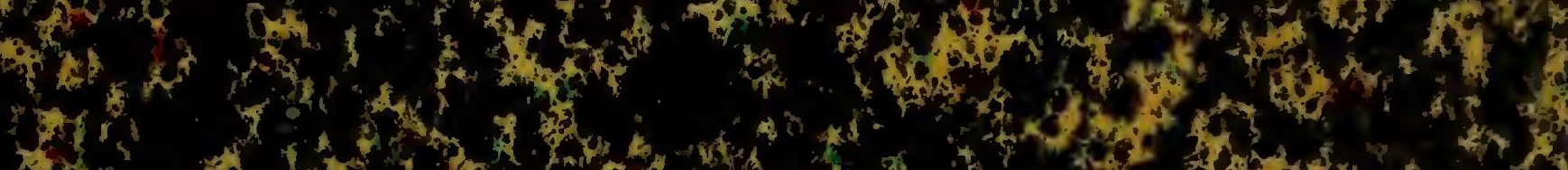

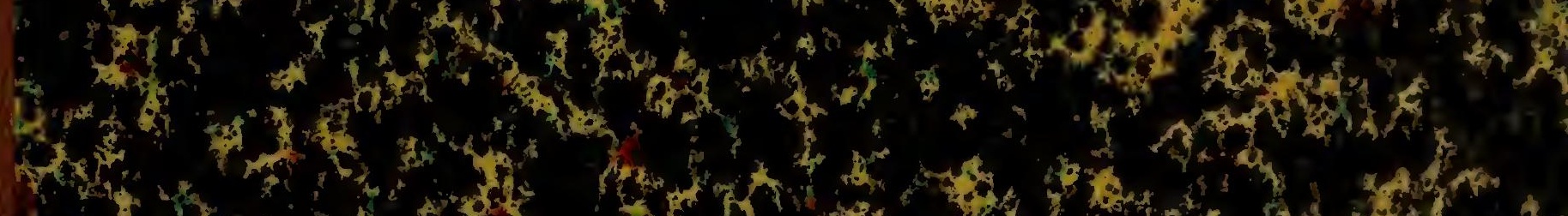

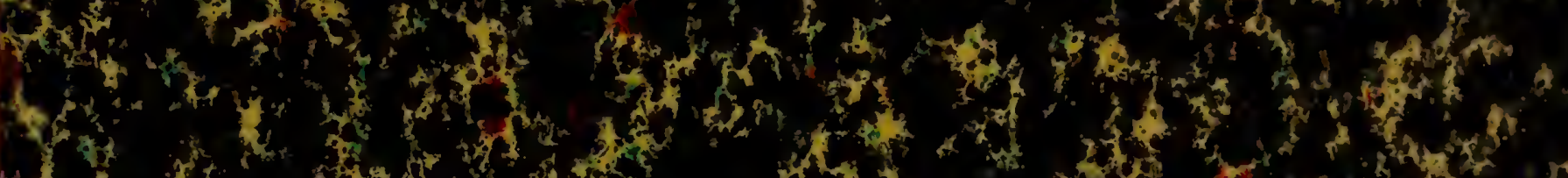

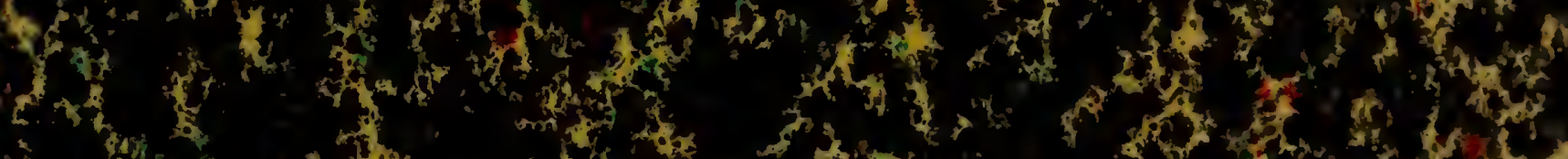

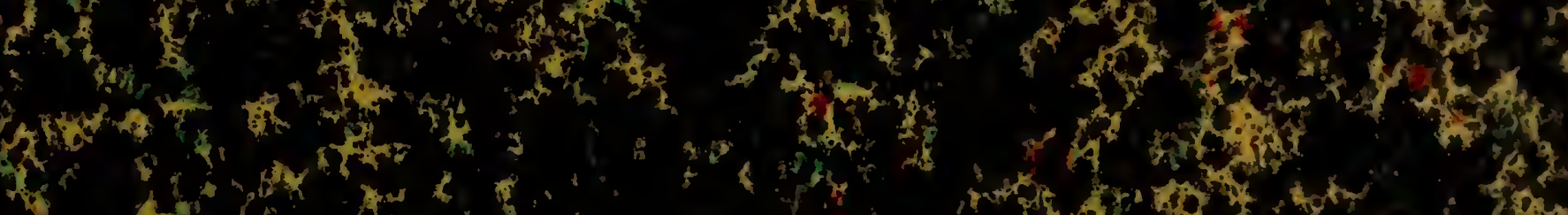

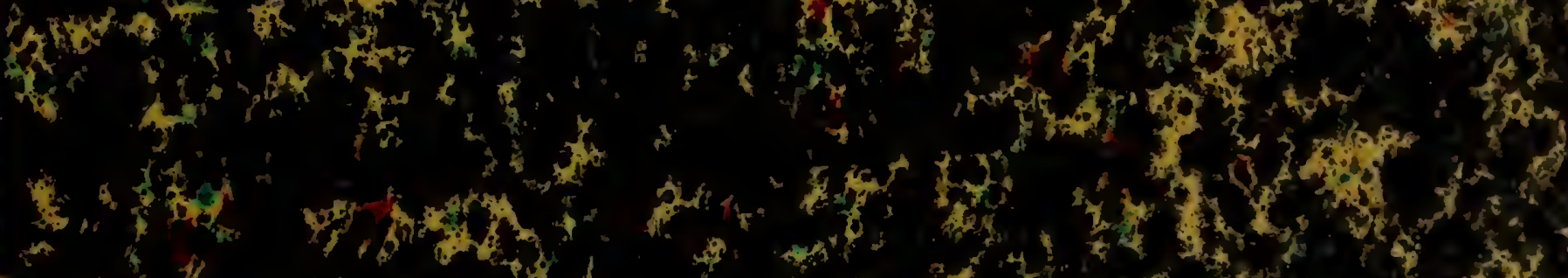

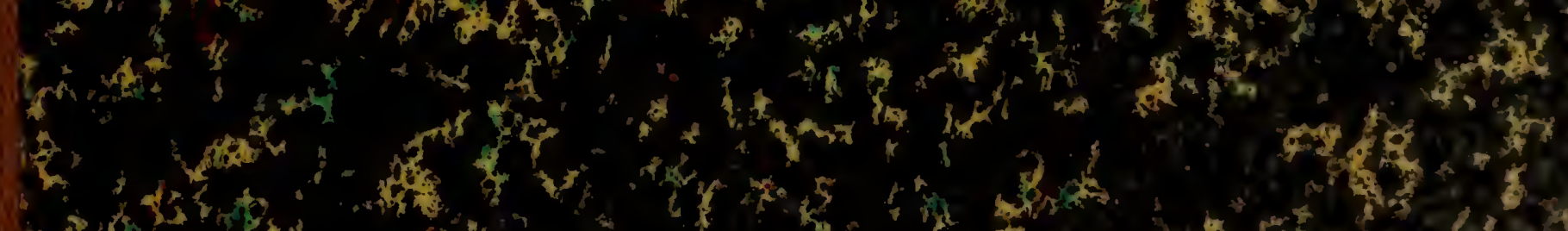
(3)

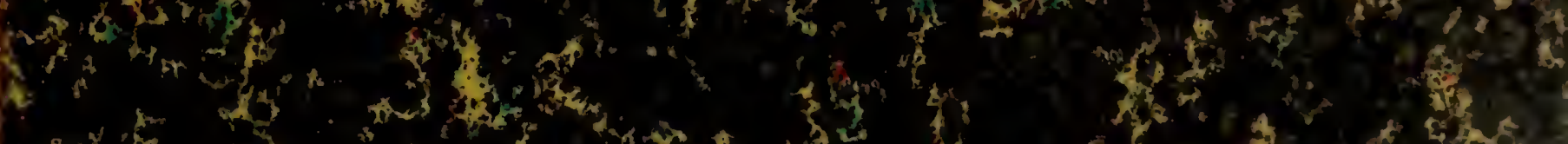

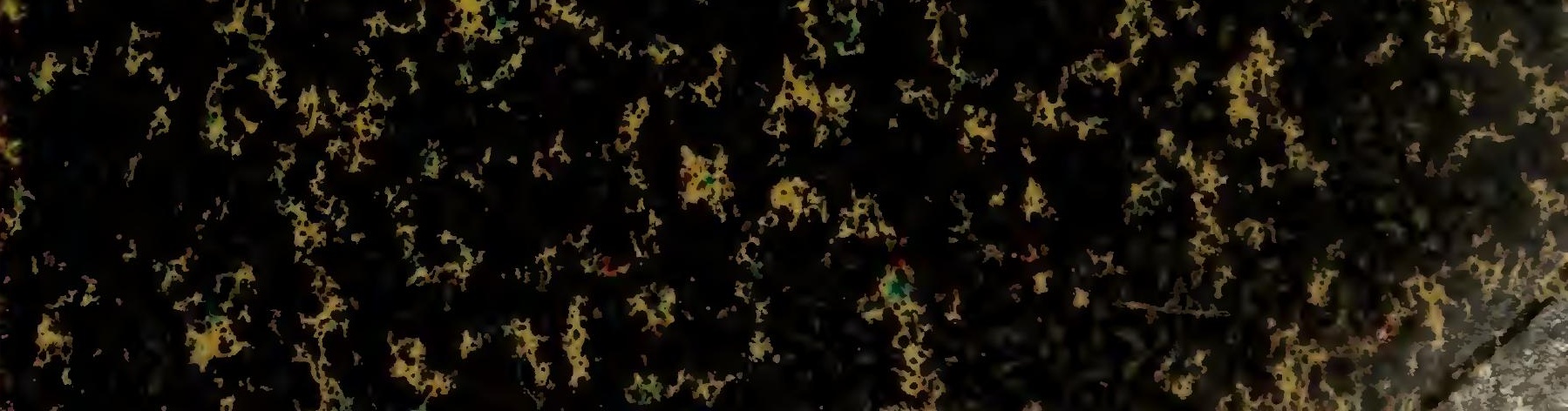




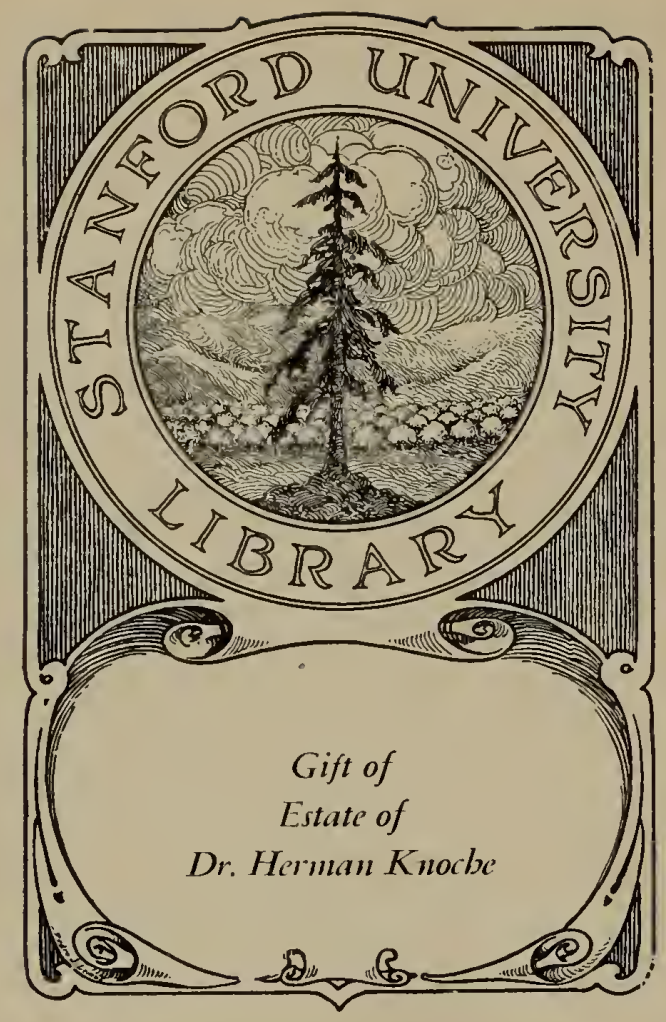

\section{California Academy of Sciences Library}

By action of the Board of Trustees of the Leland Stanford Junior University on June 14,1974 , this book has been placed on deposit with the

California Academy of Sciences Library. 




\section{PRODRO MUS \\ FLOR F FOSSILIS SENOGALLIENSIS}

A UCTORE

A. D. Profess. MASSALONGO

(Cum 4 Talb.)

h' 
750637

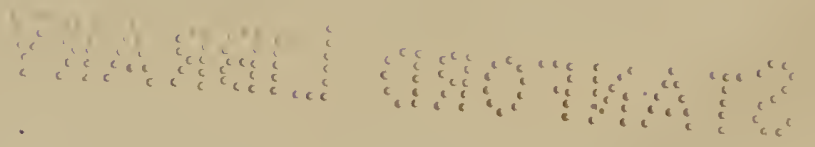




\section{$P$} diat, quem pone sequatur quadraginta fortasse ejus loci plantarum enumeratio, mirabitur procul dubio tam paueis subsidiis, tantam argumenti molem suscipi pertraetandam. Nec id injuria quum ipsemet sæepius ab loc consilio abstinere satius duxerim, et rem differendam in aliud tempus putaverim, sperans fore ut majorem speeierum numerum quandocumque in unum eongerere possem, aut eruditum aliquem rerum naturalium eognoscere, qui pluribus auxiliis adjutus locum illum celebrare aggrederetur. Sed ab anno 1849 quo a prestantissimo atque amiciss. geologo Searabelli Forocorneliensi, paucas quas deseripturus sum speeies, eum aliis permutatas aceepi, irritum spes omnis cecidit, quare confido benignitate in me usuros Italos, si viderint coneessum csse cupiditati illustrandi Floram, cujus hactenus paucas incertasque notitias habebamus. - Utinam lieeret argumentum latioribus finibus circumdare, equidem nisi vires defieerent, nisi hujusmodi indaginum amor fortasse nimius me falleret, si cives nostri majorem operam darent huic studio, quod in aliis, Europæ regionibus tantos edit progressus, quum apud nos in ipsa infantia heu! versatur, in vulgus proferre ausus essem non tam Prodromum Flore Senogalliensis, quam Floram fossilem miocenieam Italam universam: quod opus nimio nostro dedeeore nondum possideınus, quamvis natura, suas inter nos opes quascumque omni tempore diffuderit, ut non tam ejus superfieies sed viseera ipsa Europe hortum præseferant.

Quot hisee temporibus loea nostræ peninsulæ eognita sunt organicis vegetabilibus reliquiis redundantia? Abundat Trinacria tellus, abundant Pedemontium ac Hctruria et Venetæ Provinciæ, ubi tot tantasque rerum naturalium opes mihi contigit reperire. - Quare igitur non complectimur nos ea, nec conjunctim illustramus, ut flora quæ olim felices agros nostros exornabat possit cognosci? Clarissimus A. Prof. Costa Ichthiolithologiam Italicam pollicitus jam est, extant opera de molluscis aliisque animalibus fossillbus totius fere Italiæ, restat nihil aliud quam flora fossilis Itala, post quam habebimus exoptatan integram Palaeontologiam nostræ peninsulæ 
Pauci admodum ad nostram hane ætatem, naturalium seientiarum docti Itali extitere, qui plantarum fossilium studio se se unice applicuerint, et obiter tantum nonnullas passim de hisce rebus illustrationes tradiderunt: si excipias cpistolam Vivianii de Phyllitibus oppidi Stradella, Iriam inter et Placentiam, tum animadversiones Procaccini Ricci, et elueubrationem Prof. J. Bianconi, (Ann., Bonon., 1838, T. 1, pag. 343-390), qui primus in Italia plantas fossiles in ordinem redigere aggressus est, juxta nervos ac venas, eæteri omnes Savi, Meneghini, Catullo, Brocchi, Parlatore, Moretti, Brcisiak, Pilla, Santagata, Bertoloni, Meneghini, etc., etc. aliquas tantum species in suis operibus descripserunt, aut de carum in aliquo loco existentia monuerunt $\left({ }^{*}\right)$.

Non igitur examini subijciam quod in scientiæ utilitatem elari illi viri præstitere: uni me floræ Senogalliensi quæ hujus mex elucubrationis finis est dicabo. Præmittam nounullas animadversiones tantummodo in geologiam illius loci et loeorum affinium, utens seriptis Procaccini Riccii, qui pra omnibus aceuratius cognovit, et præsertin celeb. geologi Scarabelli c foro Cornelii, qui primus omnium certe statuit periodum ad quam dcbcant referri. Deinde exhibebo descriptiones paucarum specicrum, quas præ manibus haberi, aut de iis audiri contigit, quibus addam omnes eas plantas, quæ hactenus repertæ sunt ae deseriptæ in formationibus miocenicis Italiæ mihi cognitis; demum subijeianı prospectum Flora fossilis Senogalliensis cum aliis floris Europæis comparatæ.

Plura sunt agri Senogalliensis loca in quibus inveniuntur affatim plantæ fossiles, et præsertim ad S. Angclo (Cave della Canuta), Scapezzano, S. Gauden$z i o$ : constant omnia stratis quibusdam margaceis interpositis vel vicissim sibi succedentibus cum exiguis aliis stratis gypsaceis, argillosis, aut calcareis, quæ a Bononia, ad Scnogalliam, et verisimiliter, ad Asculum usque pertinent.

Juxta animadversiones doctissimi amici mei Scarabelli expositas in ejus opuseulo cui titulus Sur la formation Miscène du versantc $N$. E. de l'Appenin de Bologne et Sinigallie (Bull. Géol. de Franc. 2. ${ }^{\mathrm{c}}$ Sér. T. VIII, pag. 234 ) hæe depositiones miocenice dividi possent in tres classes, prout invicem sunt superpositæ. Prima classis offert sursum deorsum depositiones saxi molassici, conglomeratorum, et itcrum saxi molassici : secunda classis argillam, saxum caleareum et gypsum, et saxa sulphurifera: tertia classis saxa molassica, quæ sequuntur saxum quod vocant macigno, saxum calcarcum rubrum, et saxum quod appellant Scaglia. - Hine patet saxum molassicum in inferioribus ac supcrioribus partibus inveniri, ut etiam in Samnitibus animadverterunt illustres viri Spada et Ursinius (Bull. 2. ${ }^{\mathrm{c}}$ Sér., tom. II, pag. 408), quod constat exiguis granulis siliceis eonjunetis eæmento quodam argilloso, vel aliquando cæmento caleareo. - Sceus viam Bononiensem videri possunt hæc duo genera 
saxi molassici, et præsertim apud loca Praduro, Sasso-Vergato, Sogliano, Pesaro, Perticaja. - Color ctiam hujus saxi alius alibi est, luteus tamen in depositionibus recentioribus, cinereus in antiquioribus obtinet: varia etiam est stratorum crassitudo ac densitas, et nonnullis in locis mirifica (S. Marino, Monte-Bello, S. Leo), eaque accipiunt interdum formam schistosam.

Declivitas quoquc eorum varia admodum cst, sed quæ magis sunt inclinata eadem fere sunt antiquiora. Saxum Molassicum continct sæpc strata magis minusve conspicua Lignitum (Sogliano, S. Marino, S. Leo, Perticaja) et designatur fossilibus sequentibus: Lamna contortidens Ag. Oxyrhina isocelica E. Sism. O. xiphodon Ag. Carcharodon megalodon Ag. crassidens E. Sysm., polygyrus Ag. Sphcerodus cinctus Ag. Echinolampas Laurillardii Ag. Lucina transversa, Pecten scabrellus Lam. Polia legumen Orb. Conus striatulus Brocch. Mitra plicatula, Terebra duplicata, Ranella lcevigata, Natica olla, Cerithium crassum, bicinctum, Ostrea virginica, maxilla, Murex trunculus, etc. etc.

In argillis vero margaceis Senogallicnsibus quæ continent Pliyllites et Ichthiolites inventa sunt sequentia fossilia Pecten duodecim-lamellatus? Bron. Nucula concava? Bron. Chama arietina Brocc. Cardita intermedia? Lam. Corbula cuspidata Bron. Schizaster canaliferus Ag., etc., etc., et præterea species plantarum infra descriptarum.

Sub saxo molassico scquuntur ordine, duo vel tria strata conglomeratorum quæ constant ferc saxis calcareis antiquioribus, et lapidibus alius generis. Hæc conglomerata quæ ad 8 vel 10 metrorum altitudinem pertingunt, continent (Sogliano) lapides aliquos serpentinosos, et videntur interesse depositioni calcareæ superius, et gypsaceæ infcrius, quæ tamen res certa nondum plane est, quod plerumque gypsum et calcareum saxum una reperiuntur. - Ad sccundam classem gradum facio, sub saxo molassico invenítur species quxdam argillæ de qua verba fecit sane docte prof. Bianconi ct vocavit Argilla scagliosa, eaque propter uniformitatem cum stratis superioribus molassicis et inferioribus $\mathbf{F u}$ coidcis (S. Marino, Montebello) a Scarabellio ut miocenica procul dubio exhibetur. Variam multimodis illam faciunt saxa serpentinosa, et continet ubique sulphas calcis abundanter (4!/100) præter Baritina passim et gypsum lenticulare et Pyrites et Aragonites, etc.

Hæc strata argillosa diversa aliquanto sunt prope Scnogalliam (Canuta), et intersunt depositionibus margaccis fossilibus scatentibus, et saxo molassico gypsacco. Quarc rupes qux sequitur argillam, cst aliquando gypsus, aliquando saxum calcarcum margaceum fucoideum, quod aliquando eminet inter argillam et gypsum; non tamen uno semper modo, neque enim calcareum gypso semper impendet, evancscit quippe quum hic ad maximum pertingit, eminet contra quum hic vix apparet. 
Hoc saxum calcareum colore albido-lutescente pauca præbet fossilia, et distinguitur nonnullis cryptogamis aquaticis relatis a cl. Scarabelli ad Fucoides Targionii et intricatus, qui plurimi reperiuntur in M. Gelli, Giardino, M. Moggio, cte. Abstinere non possum quin mea aliqua dubia exponam de lıoc calcareo, nihil obstantibus doctis animadversionibus clarissimi Scarabelli (loc. cit., pag. 16) et Pareto (Mém. soc. Géog. fran. I Ser., tom. 1, pag. 125). Suspicio enim est ne aut calcareum sit loco non naturali, aut Fucoides sint revera aliud a supradictis. Fucoides Targionii et intricatus pertinent ut notum omnibus est ad Formationem cretce, ct proprie ad formationem saxi Albii chlorotici vei albii cœmenticii (Grünsand, Plæner, Quadersandstein, Germanorum ) et nondum quod sciam reperti sunt in depositionibus perantiquis periodi tertiariæ, idcoque co magis dubia cst corum præsentia in recentioribus. Noneo igitur géologos corum locorum ut hane rem maturius considerent, quæ tanti interest non solum gcologiæ, verum etiam botanicæ, quo possit definiri quandonam apparuerint duo illa vegetabilia, et ad quod tempus viguerint. Sub hoc calcareo inveniuntur exigua plura strata gypsacca, et sub lis constanter reperiuntur rupes sulphiferce divcrsa quidem natura, nempe aliquando sabulosæ et schistosæ, aliquando calcareo-margaccæ. Sulphur interdum symmetricas accipit formas, maxime in rimis, æque ac sulphas strontiance et sulphas calcis. Depositiones gypsaccæ Senogallienses quæ continent plantas, conchas, et pisces, diversæ prorsus sunt, ab illis de quibus verba fecimus, non tam propter structuram quam propter fossilia, sibi enim invicem succedunt sæpius cum margis fossiliferis, et argillis schistosis, sub quibus cxistit marga calcarea-silicea, quæ forte idem est, ac supradicta rupes calcarea fucoidea. Sulphur hic repcritur quamvis in pulverem conversum, in rimis simul cum mineralibus supradictis. Sub his depositionibus gypsaceis iterum apparet saxum molassicum codem ordine ac natura. In agro Foro Corneliensi hæe strata distinguuntur dentibus Carcharodon Grassidens E. Sism. angustidens Ag. Lamna contortidens Ag. et Pectinibus Scabrellus Lam. Pectunaculus glycimeris et specicbus indeterminatis generum Trochus, Buccinum, Tellina, etc. In depositionibus Senogalliensibus abundant plantæ fossiles, præsertim quæ pertinent ad Cupuliferas, Acerineas, et Balsamifluas.

Qui plura desiderat de his depositionibus quæ ut norunt omnes pertinent ad periodos a Brocchio assignatas ad ejus formationem Subappenninam, consulat opera quæ retulimus in hac lucubratiuncula, et præscrtim animadversiones cl. Scarabelli a quo ferme ad litteram res præcipuas exccrpsimus. Quod ad depositiones Senogallicnses consulantur præ cætcris quæ scripserunt, Procaccinus Riccius, Marsilius, Passerius, Spadonius, ct Acta primi Congrcssus doctorum italorum (pag. 69). 
Tandem animadvertam, depositiones etiam prope Papiam (Stradella) pertinere procul dubio ad eamdem formationem gypsorum Senogalliensium, ideoque tum illas tum has referri debere ad periodum miocenam, æquæ ac HcIruscas ( M. Bamboli e M. Massi) in quibus omnibus locis extant plantæ fossiles quas infra describam.

Veronæ IV idus Januarias 1833.

\section{P R O D R O N U S}

PALMAE.

FLABELLARIA STERNB.

\section{Flabellaria spathulata Massal.}

FL. Foliis longe petiolatis flabellato-pinnatis, pinnis rhachidi triangulari-cuneatæ pollicari, insidentibus, numerosis congestis, radiatim plicatis indivisis, margine repandis, petiolo tereti, apice dilatato.

Syn. - Uraniophyllites spathulata Savi. Miscell. di chim. fisic. e stor. nat. N. 3, Pisa, 1843. - Savi, Sopra $i$ carboni fossili delle Marem., pag. 55, tab. 1, fig. 8. - Flabellaria Saviana Parlat.? Lett. al Prof. Savi 1. luglio 1843. - Savi, loc. cit., pag. 67-68.

Abit. In schisto calcareo photido ad M. Bamboli Italiæ.

Observat. Absque dubio nova est hæc species, sed incertus lıreo, an ipsa vere sit species quam Prof. Parlatore intellexerit Prof. Savi dicare. Quum hæc species mihi non aliunde cognita sit, quam propter diagrammata edita a Prof. Savi, eadem causa præbere majorem illustrationem nequeo, et remittendus milii lector est qui optaret eam penitius cognoscere, ad superius citata opera.

Flabellaria Parlatorii Nassal.

FL. Foliis longe petiolatis flabellato pinnatis, pinnis rhachidi triangulari-cuneatoacuminatæ pollicari insidentibus, numerosis, basi congestis, apice divisis, linearibus angustis, integris, bifidisque, radiatim plicatis, petiolo tereti æquali.

Synon. - Flabellaria raphifolia Parlat. (Non Sternb.) Lett. al Prof. Savi, loc. cit. - Savi, loc. cit., pag. 67-75, tab. Il, fig. I.

Abit. Cum priore.

Observ. Clar. Professor Parlatore retulit hujusmodi speciem in M. Bamboli inventam ad Flabellariam Raphifoliam Sternbergii: multis tamen de causis oponio ejus non mihi videtur amplectenda. Et in primis Flabellaria 
Raphifolia Sternb. præsefert folia ad petiolum usque divisa, et rhachidem arcuatam obtusamque, quæ duo desunt omnino in specie a Prof. Savio depicta, quæ ut ipse scripsit atque optime depinxit, ante oculos obijcit rhachidem formæ triangularis, cum vertice peracuto, et laminam folii in lacinias partitam, quæ una simul adnectuntur, multo antequam perveniant ad basim petioli. Dicendum potius est inter cognitas species, Flabellariam Parlatorii accedere ad Flabellariam Lataniam et Oxyrhachidem, quin tamen hane vel illam imitetur.

\section{CUPRESSINE}

TAXODITES UNG.

Taxodites dubius Sternb.

Tab. nost. IV, fig. 6.

T. Ramulis teretibus, foliis approximatis alternis oppositisve, breviter petiolatis lineari-lanceolatis planis uninerviis, utrinque acutis, inferioribus triplo brevioribus, lanceolatis (Amentis staminiferis subglobosis plurimis in spicam terminalem dispositis, strobilis ovato-oblongis terminalibus, squamis sublignosis.) - Ung. Gen. et spec. plant. foss., pag. 351. - Iconogr. plant. foss. tab. 10, fig. 1-7. - Stern. vers. II, pag. 204.

Syn. - Phyllites dubius Sternb. vers. 1, 3, pag. 37, tab. 36, fig. 3-4 Index (tab. 24, fig. 2?) Taxodites pinnatus Ung. - Synops. pl. foss., pag. 194.

Abit. In schisto margaceo ad Senogalliam Italiæ, in argilla plastica et jaspoide ad Bilinum Boemiæ, nec non ad Parschlug Stiriæ.

Obser. Meum exemplar consistit in ramusculo longitudinis vix duorum pollicum, et secum affert 15-16 foliola utroque latere clara ac distincta, et nervulum medianum valde conspicuum. Inter species viventes adsimilatur Taxodio distico Rich.

THUITES UNG.

Thujtes Spec. Ind. Savi.

Loc. cit., pag. 74, fig. 9-10, tab. 1 .

Abit. In argilla cinerea miocenica agri Florentini ad N1. Vaso (Botro-Lavajano), nec non in argilla bituminosa ad Caniparola Italiæ.

Observ. Non satis bene depicta hæc species conspicitur, ut quis possit judicium proferre de ejus specifica essentia; certum tamen cst ipsam ad genus Thujtes spectare. 


\section{ABIETINEE. \\ PINITES ENDL. \\ Pinites Saturni Göpp. \\ Tab. nost. II, fig. 4.}

P. Foliis ternis acerosis elongatis rigidis, vaginis productis. (Strobilis aggregatis pedunculatis patentiusculis ovato-conicis, squamarum apophysi depresso-pyramidata transversin rlımbea, umbone plano rlıombeo-umbonulato.) Ung., Gen. et sp. pl. foss., pag. 362. - Göpp. in Bronn. Gesch. d. Nat. III, 2, pag. 41. - Endl. Synops. Conif., pag: 286.

Synon. - Pinus Saturni Ung. Chl. Prot. pag. 16, tab. 4-5. - Pitys Saturni Ung. Syn. pag. 198.

Abit. In stagnigeno gypso ad Senogalliam Italiæ, nec non in calcareo argillacco ad Rodobojum Croatiæ.

Observ. Valde corruptum est fragmentum, quo usus sum in examine, quodque imperfecte, ibidem depictum fuit. - Nullum tamen dubium relinquit quoad cjus determinationem, quoniam diligenter intuenti apparent optime omncs ejus charactercs.

\section{Pinites Urani Ung.?}

P. Strobilis ovalibus? ( 2 poll. long., 1, 5 poll. lat.), squamarum apophysi deflexa, carina transversc elevata, latere superiore convexiore, umbone parvo mutico? (Seminum ovatorum magnorum, ala lanceolata-obtusata.) Ung., Gen. et Spec., pag. 363. - Icon. pl. foss., pag. 26-27, tab. 14, fig. 5-6. - Savi, loc. cit., pag. 76 , tab. II; fig. 12 ?

Abit. In calcareo molassico ad il. Massi Italiæ, nec non in schisto margaceo ad Rodobojum Croatiæ.

Observ. Valde incertum est utrum hæe spccics quam clar. Savius depinxit, spectet ad novas aut ad cognitas generis Pinites, et ut res absolveretur opus esset exemplaria habere præ oculis. - Inter specics adhuc cognitas convenit præcipue cum Pinile Urani Ung. etsi ejus squamæ valde majores sint ac diversimodc dispositæ, indicia e quibus judicari potest hoc quoque fossile pertinere ad novam quamdam spcciem generis de quo quæstio est. Alicui forte videbitur minus æquum, ac audax judicium quod protuli simplicibus tantummodo innixus diagrammatibus, quxque ctiam haud perfecta sunt; sciant tamen omnes me id facere ad hoe ut ii qui ea possident fossilia, omnem in is perquirendis curam adhibeant. 
Pinites Spec. Ind. Savi.

Loc. cit., tab. II, fig. 10. - Miscel., loc. cit., N. $\pi$.

Abit. In schisto calcarco ad M. Massi (Fonte al Tamburino) Italiæ.

Observ. Absquc dubio spectant ad genus Pinites, parvæ illæ imagines alatx quæ conspiciuntur in figura decima tabulæ secunda operis Clar. Savi superius citati. - In incertn tamen res adhuc est, utrum eæ pertineant ad novam aliquam spcciem, an vero ad cognitas, et ut res definiatur apporteret exemplaria præ manibus hábere, proximæ tamen sunt Piniti Goethani Ung. Una cum hisec Pinites imaginibus, cernitur quoque typus quidam linearis oblongus, quibusdam transversis appendicibus præditus. Ipse fortc esse potest aquatica planta et probabiliter species generis Drepanophici Göpp. ( aut Pinnularice Lind. et Hutt.?)

ARAUCARITES STERNB.

Araucarites Sternbergii Göpp.

Tab. nost. IV, fig. 9.

A. Ramis sparsis, foliis ovatis acutis v. acuminatis subfalcatis, basi decurrentibus imbricatis, apicc patentibus. Ung., Gen. et Sp., pag. 381 - Göpp. in Bronn. Ges. d. Nat., pag. 41, III. - Massal., Sopra le piante foss. del Vicent., pag. 110. - Ung. Fl. von Sotzka, p. 157, tab. 24, fig. 1-14. - Tab. 25, fig. $1-7$.

Synon. - Cystoseivites dubius Sternb. vers. II, tab. 9, fig. 5-6, tab. 17, fig. 1.Cystoseirites taxiformis. Stern. ver. II, tab. 18, fig. 1-3. - Iuniperites? cespitosus Brong. of the Soc. Ged. VII, p. 373. - Lycopodites caspitosus Schl. petref., p. 416.

Abit. In stagnigeno gypso ad Senogalliam, in schisto margaceo ad Salcedo et Chiavon agri Vicentini Italiæ, nec non ad Haring Tirolis et Sotzka stiria.

Olsserv. Parvum quidem est hoc fragmentum depromptum ex gypsis Senogalliensibus, attamen sufficit ut existentia eo loci probetur hujus speciei. Si quis optaret de hac specic aliquod præterca cognoseere, lcgat ca qua ediderunt supra dicti auctores, quodque egomet in lucem protuli, pag. 110-113 mearum Osservazioni sopra le piante fossili del Vicentino (Patavii, 1851). 


\section{TAXINE E.}

TAXITES BRONG.

Taxiles Langsdorfi Brong.

Tab. nosl. : , fig. 10.

T. Holiis linearibus subsessilibus acuminatis confertis, nervo medio valido a stomatibus resiniferis paginam inferiorem dense obsidentibus discreto. Ung., Gen. et Sp., pag. 389. - Brong., Prod., p. 108-208. - Ung., Iconog. pl. foss., tab. 15, fig. 13. - Eutings, Beitrag zur foss. Fl. von Wilds., pag. 6, tab. 1, fig. 1. - Weber, Die Tertiär. Flor. der Nied., tab. I, lig. 8-9, pag. 52. - Ui1g., Blütterung. von Swosrow, tab. 13, fig. I. - Göpp., Monog. der f. conif., pag. 246.

Abit. In gypso stagnigeno ad Senogalliam Italiæ, ad Niddam prope Francofortum, ad Rott et Quegstein prope Bonnam, ad Zilingslorf prope Neostadium Austrị, ad Vindobonam, ad Swoszowice Galiciæ, nec non ad Wildsuth.

Observ. Hæc species simillima Cupressit. taxiformi Ung. ejusque Taxitide Rosthorni ncc tamen par, est una ex communioribus coniferis quæ repcriuntur in periodis tertiariis Europa, ut videre est ex pluribus locis antea citatis; strata quoque gypsacea Senogalliæ haud ipsa carcnt, quin immo quarn maxime abundant. Foliola in meo exemplari obtusiuscula evadunt. ac nervum medium satis conspicuum demonstrant.

S.ALISBUHA SHTH.

\section{Salisburia adjantoides Ung.}

S. Foliis late rhomboideo-subfiablliformibus (bipollicaribus) in petiolum angustatis integris sublobulatisve, flabcllatim nervoso-striatis. - Ung., Gen. et spec. pl. foss., pag. 392.

Syn. - Ginko biloba. Procacc. Ann. Sc. Nat., Bol., 1838, T. I, tab. IV, fig. 3, pag. 209, N. 62.

Abit. In formatione tertiaria miocenica ad Senogalliam Ilalix.

\section{BETULACEA.}

BETULA TOURN.

\section{Betula Driadum Brong.?}

B. Foliis ovato-acuminatis denticulatis. - Ung., Gen. et sp., pag. 397. - Brong. Prod., pag. 143-214. - Ann. Sc. Nat. XV, pag. 45, tab. 3, fig. 5. - Ung. 
chl. Prot. tab. 34, fig. 2-5. - Viviani, Mém. Soc. Géol. de Fr., T. I, p. I, N. VII, tab. X, fig. 6 ?

Abit. In stagnigeno gypso ad Stradellam prope Papiam Italiæ.

Observ. Valde imperfcetum cst fragmentum folii depictum a Vivianio in $\mathbf{M} \dot{e}-$ moires Societatis Gallicæ Geologicæ, quod ego dubium refero ad speeienı. de qua quæstio est. Consultius forte esset nihil de eo dicere, nisi ad id me impelleret spes permovendi eos in quorum manibus sunt exemplaria authentica ad examinanda objecta a majoribus nostris delineata ae descripta.

\section{ALNUS TOURN.}

\section{Alnus Suaveolens Viv.}

A. Foliis petiolatis orbicularibus obtusis crenatis? penninervis, nervis sceundariis simplieibus parallelis. - Ung., Gen. et sp. pl. foss., pag. 398. - Viv., loc. eit., pag. 131, fig. 3 , tab. IX.

Abit. In stagnigeno gypso ad Stradellam prope Papiam Italiæ.

Observ. Folium longum paulo plus duobus pollieibus, latum unum pollicem et quatuor lineas, forma orbiculari obtusa, et fortasse ad margines crenatum, præditum eminenti ac conspicuo nervo mediano, et nervis sccundariis oppositis simplicibus parallelis.

\section{ALNITES GÖPP.}

\section{Alnites Venosa Massal.}

Tab. nost. IV, fig. 2.

A. Foliis ovato-ellipticis penninerviis, margine late crenatis, apice obtusis, nervis seeundariis sub angulo aeuto e nervo primario cgredientibus, 5-6 mil. inter se remotis, venis crassis sub angulo recto orientibus, inter se conjunetis, et rete venoso conspieuo irregularitcr rhombeo-tctragono efformantibus.

Abit. In stagnigeno gypso ad Senogalliam Italix.

Observ. Hoe folium tantam eum foliis aliquibus Betulaceis affinitatem præfert ut nullum sit dubium de ejus detcrminationc. Accedit inter fossiles plantas ad Fagum Feronia Ung., Arthocarpidium olmedicefolium Ung. , Carpinum productam Ung., et Arthocarpidium cecropœfolium Etting; et præsertim ad Alnitem emarginatam et pseudoincanam Göppertii, ita tamen ut ad omnibus differat. Iaetura est folium haud integrum esse, quare nihil dici potest de ejus petioli longitudine.

Observatione dignum est in hac phyllitide rete venosum, forte admodum ac conspicuum. 


\section{Alnites incerta Massal.}

A. Foliis subcordato-oblongis integriuseulis, brevissime petiolatis acutiusculis pennincrviis, costa valida, nervis oppositis alternisve sub angulo 25-30 orientibus, 5-8 mill. inter se remotis, venis (nonnumquam obsoletis) sulb angulo obtuso egredientibus. - Viv., Mém. Soc. Géol. de Fr., loco citato, Tab. IX, fig. 1-2.

Abit. In stagnigeno gypso ad Stradellam prope Papiam Italiæ.

Observ. Inccrtum valde est debeat ne hoc folium Betulaccis adseribi, neque definire tuto possem eum quibus hujus familiæ generibus connumerari debeat, mclius quam cum Alno Iorullensi Kunth. mexicana, quæ aliqua ex parte similis esse videtur. - Alnus suaveolens Vivianii dici ne debet species distincta, an fragmentum lıujus typi media ex parte abrupti? Hæe phyllites longa est tres circiter pollices et lata unum ejusque tertiam partem, leviter cordata, crassis iisque conspicuis nervis, et vestigiis rudis cujusdam retis venosi. Inter species fossiles accedit ad Alnum Diluvianum Ungeri.

\section{CUPULIFER $/$.}

QUERCUS $L I N N$.

Quercus drymeja Ung.

Tab. nost. 1II, fig. 1 .

Q. Foliis longe petiolatis oblongo-lanceolatis utrinque attenuatis cuspidatodentatis glabris, penninerviis. Ung., Gen. et spec., pag. 400. - Chl. Pro. tab. 32, fig. 1-4. - Fl. v. Sotzka, tab. 8 (29), fig. 1-2, pag. 33 (163).

Abit. In gypso stagnigeno ad Senogalliam ad Stradellam prope Papiam Italix, nee non in sclisto calcareo ad Solzka, Parschlug, Sagor et in aliis locis.

Observ. Fateor hæsisse me plurimum, quoad determinationem hujus Phyllitidis, quum invenerim plures similitudines præter quam cum Quercu drymeja Ung., ctiam cum diagrammatibus Comptonice ulmifolia, Iuglandis hydrophila ejusdem auctoris: tamen ad primam retuli ob formam marginum, dentes multo minus acutos preferentium, quam Comptonia ulmifolia, et ob majorem frequentiam nervorum, corunque minorem numerum in Iuglande hydrophyla.

Tamen similitudo Quercus Drymeja cum foliis Comptonia asplcenifolia et Iuglandis aquatica hodie vigentium, incertum admodum relinquunt debeat ne hæc plıyllites cum genere Quercu collocari. 


\section{Quercus uropliylla Ung.}

Tab. nost. 11, fig. 8 .

Q. Foliis ovato-lanceolatis basi productis acuminatis subcoriaceis curvatisque penninerviis, inæqualiter dentatis, dentibus conspicuis obtusiusculis apice sursum flexis. Ung., Gen. et Spec., p. 403. - Fl. v. Sotzka, p. 33, tab. IIl, fig. 9-14. - Massal. Piant. foss. del Vincent., pag. 131.

Abit. In stagnigeno gypso ad Senogalliam, in schisto margaceo ad Salcedo et Chiavon, agri Vicentini, Italiæ, nec non ad Sotzka et Parschlıg Stiriæ. observ. Folia Iuglandis elanoides, Ung. Driandroidis hakaeefolia ejusdem auctoris, et etiam Quercus Lorchitis Ung., et præcipuæ forma depicta a Webcrio (Die Tertiür. Fl. dier. Nied., tab. 1, fig. 16, Cassel, 1852), nec non Quercus Urophylla præseferunt omnia similitudinem cum meo typo, et eadem Castanea atavia, quare judicent alii num ipse jure collocaverim hane phyllitidem sub specie de qua disseritur, cum qua re vera majorem exhibet quam cum cœteris similitudinem.

\section{Quercus myrtilloides Ung.}

Tab. nost. Il, fig. 11.

Q. Foliis pollicaribus petiolatis ovato-lanceolatis obtusis integerrimis, coriaceis, nervo primario distincto, nervis secundariis nullis. - Ung., Gen. et Sp., pag. 404. - Iconog. pl. foss., pag. 38, tab. 18, fig. 17-20.

Abit. In gypso stagnigeno ad Senogalliam Italiæ, nec non in schisto calcareo ad Parschlug Stirix.

Observ. Folium longum paulo plus uno pollice (in meo cxemplari $11 / 2$ ), forma ovato-lanceolata, margine integerrimo, et costa prædistincta, absque nervis. - Inter species vigentes accedit ad Quercum myrtifoliam Wild. Americæ septentrionalis.

\section{Quercus Senogalliensis Massal.}

Tab. nost. 1, fig. 2, et Tab. IV, fig. 10.

Q. Foliis late lanceolatis inciso-sinuatis integerrimis, utrinque attenuatis sul integris breviter petiolatis, acuminatis, costa valida, nervis sub angulo acuto cgredientibus $8-10$ mill. interse remotis, leviter areuatis, venis subangulo recto egredientibus inter se conjunctis.

Abit. In stagnigeno gypso ad Senogalliam Italix.

observ. Nullum relinquit dubium hujus phyllitidis determinatio, cum tantan præseferat similitudincm cum foliis Quercuum hodie vigentium, quarum tanıen characţeres non exhibet, excepta quadam analogia cum foliis 
Quercuum Prinos et acuminato. Inter species fossiles accedit ad Quercum pseudo-castaneam Göpp. (Beiträg. zur Tertiär. Fl. Sch., tab. III, fig. 1-2), quæ tamen minus acuta est, cum dentibus in margine acutioribus, et nervis frequentioribus.

Folium Quercus Senogalliensis longum est 4 vel 5 pollices, latum paulo plus uno pollice cum dimidio. - Excmplar a me depictum in tabula $\mathbf{1}$, fig. 2, non offert vestigia venarum, sed habet distinctos eosque alternos et parallelos nervos laterales, qui 8 vel 10 in utroque latere numerantur; exemplar vero depictum in tab. IV, fig. 10 offert indicia venarum, et partem ipsius petioli.

\section{Quercus deformis Massal.}

Q. Foliis oblongo-lanceolatis obsolete-lateque-repandis incisisve, margine integerrimis, apice ovato-acuto, costa valida, nervis tenuibus parallelis simplicibus distantibus oppositis alternisve, sub angulo $35-80^{\circ}$ e nervo primario egrendientibus, apicibus inter se conjunctis.

Sin. Ulmus campestris. Biancon. Sist. Vas, delle Fill. Ann. di Bol. vol. I, 1838 , pag. 387 , tab. XII, fig. II.

Abit. In marga calcarea-arenoso Montis S. Joannis et M.Pragatto in agro Bononiensi Italiæ.

Observ. Nullum dubium est quin hac species referri debeat ad genus Quercus: longa cst 4 circiter pollices, lata unum vel unum cum dimidio, margine inæquali, varic repando, nervis raris oppositis alternisve, simplịcibusque et apice tantum divisis et inter se conjunetis.

\section{Quercus zelkovefolia Massal.}

Tab. nost. 111, fig. 9.

Q. Foliis breviter petiolatis basi subæqualibus ovato-oblongis, v. leviter subcordatis dentatis, penninerviis, nervis secundariis numerosis subsimplicibus.

Synon. Ulmus zelkovafolia Ung. Gen. et Sp. pl. foss., pag. 411.-Chl. Prot. tab. 24, fig. 7, et tab. 26, fig. 7. - Web., loc. cit., tab. 2, fig. 6. - Quercus oreadum. WVeb. dic Tert. Flor. der Nied., tab. I, fig. 13.

Abit. In gypso stagnigeno ad Senogalliam Italiæ, in sehisto ealeareo ad Parschlug Stiriæ, nec non ad Vindobonam et alibi.

Observ. Neum exemplar idem est cum exemplari depieto in tabula 26, fig. 7. Chloris protogece ita ut unum videatur. Claris. D. Ettingshausen in sua Flora fossili Windobonensi censet hæe folia potius quam ad genus ulmus referri debere ad genus Planera cum quo etiam conjugeret Ulmum pàr- 
vifoliam A. Braun. Ulmum pralongam Ung., Fagum atlanticam Ung., et ipsam Comptoniam ulmifoliam Ung. Doctissinı ejus argumenta equidem miror, sed fateri debeo persuasum mihi esse non posse, folia omnia ab ipso sub sua Planera Ungeri relata, pertinere ad unam eamdemque plantam debere. - Puto contra Fagum allanticam et Ulmum prolongam esse proeul dubio species insignes ae distinetas, et figuras 5-6-7-10-11-12-15 esse quidem unum ae idem cum Ulmo zelkovafolia, sed ejus figuras 8-13-14-16 (Fl. von Wicn, tab. 2) referendas esse fortasse tantum ad Zelkovam Ungeri, ad quam redigerem etiam folia depicta in Chloris porotogae 9-13, tab. 24, et fig. 19, tab. 20 Iconographice plant. foss., et fig. 8-9-1 3-14-1 6 Florce fossilis Windobonensis, tab. II. - Ego vero lianc speciem retuli potius ad genus Quercus, quia idem prọsus cst ae Quercus oreadum Web. quæ (ni fallat icon) præfert parvam quandam glandulam ad basim folii, quare nullum relinquetur dubium, de hac phyllitide, - Neseio tamen quo modo factum sit ut Weberus id non senserit, neque suspicaretur de similitudine suæ speciei eum Ulmo Zeckovafolice Ungeri, nihil enim de hac re loquitur pag. 58 sui operis Tertiär flora der Niederheinischen Braunkholenformation.

Quercus Papiense Massal.

Q. Foliis ovato-ellipticis inciso-serratis dentibus cuspidatis, basi in brevem petiolum attenuatis, apiceque ovato-obtuso integris, eosta conspicua, nervis simplicibus parallelis $8-10$ mill. inter se remotis sub angulo $30-35^{\circ}$ orientibus. - Vivian. Mem. Soc. Géol., loc. cit., tab. XI, fig. 7.

Abit. In stagnigeno gypso ad Stradellam prope Papiam Italiæ.

Observ. Folium longum plus quam tres pollices, latum duos eireiter : forma ovato-elliptiea ad basim dilatata et integerrima, apice obtuso, marginibus utrinque dentato-cuspidatis, dentibus arcuato-adscendentibus. Ejus similitudo cum speciebus hodie vigentibus generis Quercus et potissimun cum illis Amerieæ Borealis, mirifica.

\section{Quercus serra Ung.}

Tab. nost. IV, fig. s.

Q. Foliis longe petiolatis rigidis subcoriaceis ovato-cllipticis acuminatis dentatoserratis dentibus subæqualibus apice callosis. - Ung., Gen. et Spec., p. 400. Chl. Prot. tab. 30, fig. 5-7.

Abit. In gypso stagnigeno ad Senogalliam Italix, nee in selisto caleareo ad Parschlug Stiriæ.

Observ. Meo exemplari deest pars inferior, quare longitudinem petioli, deter- 
minarc tuto nequeo. Quercus mediterranea, Alnus gracilis, Carpinus macroptera Ung. offerunt quidem aliquan cum meo fragmento similitudincm, sed non eamdeın quam Quercus serra supradicta.

Quercus meditcrranea Ung.

Q. Foliis breviter petiolatis sub-cordato-oblongis acuminatis obtusisque, mucronato-dentatis nitidis penninerviis. - Ung., Gen. et Sp., pag 406 . Chl. Prot. tab. 32, fig. 5-9. -- leonog. pl. foss., tab. 37, fig. 1-6.

Abit. In stagnigeno gypso ad Senogalliam Italix, nec non in schisto margaceo ad Parschlug Stirix.

\section{FAGUS TOURN.}

\section{Fagus Viviani Ung.}

F. Foliis ovato cordatis obtusiusculis obsoletc dentatis penninerviis, nervo primario recto nervis secundariis subsimplicibus parallelis. - Ung., Gen. et Sp., pag. 406.

Syn. -- Fagus.... Viv., Mém. Soc. Giéol. de Fr., loc. cit., pag. 132 , fig. 12 , tab. 11.

Abit. In stagnigeno gypso ad Stradellam prope Papiam Italia.

Observ. Incerta admodum est hac spccics; cjus cnim characteres convenire possent cum multis e phyllitidibus cognitis, cum ccrta prorsus non sit rcstauratio a Vivianio excogitata, et possit esse vel non csse cordata. Casu vero quo recta esset restauratio, potius quam ad Fagum ad genus Alnum meo quidem judicio pertineret.

Fayus Faujassi Ung.

F. Foliis ovato-lanccolatis acuminatis integerrimis pennincrviis, nervo primario recto, nervis secundariis subsimplicibus parallelis. - Ung., Gen. et Sp., pag. 406.

Syn. - Castanea .... Faujas, Ann. Museum de Ilistoire Nat. II, pag. 343. Croizet, Bull. géol., 1833, IV, p. 22-26. - Viviani, Mlém. Soc. Géol., etc., pag. 122, tab. 11, fig. 10.

Abit. In stagnigeno gypso ad Stradellam prope Papiam Italix, in schisto margaceo ad Rochesaave et Ravet, nec non in terra lignitum ad Menat Gallix.

Observ. Eque ac supcrior incerta est hæc specics, nam Vivianius fragmentum tantum superioris partis folii repræsentavit.

\section{Fagus Deucalionis Ung.?}

F. Foliis pctiolatis ovatis acuminatis argutc serratis penninerviis, ncrvis secundariis e nervo primario sub angulo acutiusculo egredientibus, simpli- 
cibus parallelis, alternis, parum curvatis. - Ung., Gen. et Sp. pl. foss., pag. 405. - Chl. Prot., tab. 27, fig. 1-4.

Syn. - Fagus sylvatica. Bianconi, Sist. vasc. etc., pag. 386, tab. XII, fig. I. Ann. di Bologna, 1838, T. I.

Abit. In gypso margaceo Senogallice et Forilivii Italiæ, nec non in arenaceo ad Putschirn Bohemiæ et Parschlug Stiriæ.

observ. Certe prorsus tribui non potest hæc species Fago Deucalioni Ung., eo quod icon a Pr. Bianconio cxhibito haud satis expressus est, tamen inter species cognitas ad ipsam propius accedit.

CASTANEA TOURN.

Castanea atavia Ung.

Tab. nost. III, fig. 2-4.7.

C. Foliis oblongis obtusiusculis v. acutis, basi angustata inæquali petiolatis, grosse dentatis, nervo primario stricto, nervis sccundariis simplicibus pinnato. Ung., Fl. v. Sotzk, tab. 10 (31), fig. 5-7, pag. 34 (164). - Procacc., Anot. delle fill. Ann. di Bol., T. II, 1838, tab. II, fig. 3.

Abit. In gypso margaceo ad Senogalliam Italiæ, nec non in schisto margaceo ad Sotzka Stirix.

observ. Exemplaria hujus speciei quæ describo, sunt variæ magnitudinis, et quæ tantum rcpræsentantur fig. 2-7 sunt perfecta; quarta enim multo adultior medio fracta est. Ncrvi omnes conspicui, et tantum in fig. 4 videntur indicia venarum quæ exiles oriuntur sub angulo recto, e nervis secundariis. - Inter species vigentes congruit hæc planta fossilis cum Castanea pumila Mill. Amcricæ septentrionalis.

CARPINUS LINV.

Capinus grandis Ung.

Tab. nost. III, fig. 3.

C. Foliis petiolatis ovato-oblongis subcordatis acuminatis duplicato-scratis penninerviis, ncrvis simplicibus rectis parallelis (involucro fructifero trilido, laciniis linearibus obtusis nervosis, intermedio productiore, nervis in qualibct lacinia tribus subparallelis subæqualibus, rete venoso inter se conjunctis) - Ung., Gen. et Spec., pag. 409 - Icon. pl. foss., tab. 20, lig. 2-5.

Syn. - Phyllirea latifolia Procaccini. Ann. Sc. Nat., Bol., 1838, T. I, tab. V, fig. 2, pag. 210, n. 64 .

Abit. In gypso stagnigeno ad Senogalliam Italix, nec non in calcareo ad Rodobojum Croatiæ, et Trofeiach Stiriæ. 
Observ. Hæc pulcherrima species, cujus cl. Unger descripsit et delineavit fructus ipsos, præscfert folia lanceolato-oblonga, interdum cordata, prædita brevi petiolo, et marginibus duplicato-serratis, nervis distinetis. quorum laterales sunt paralleli et oppositi, et oriuntur sub angulo acuto e nervo mediano. Meum exemplar si integrum essel, perveniret ad longitudinem duorum pollicum ct eo amplius, et ad latitudinem vix unius pollicis.

\section{ULMUS LINN}

Ulmus affinis Massal.

Tab. nost. IV, fig. 8.

U. Folliis breviter petiolatis, lanecolatis acutis, scrratis, penninerviis, latere baseos superiori reete truneatis, inferiori rotundatis, eosta valida, ncrvis simplicibus areuatis æquidistantibus.

Abit. In stagnigeno gypso ad Senogalliam Italix.

Observ. Folium hoc proeul dubio pertinet ad Ulmaceas, et exhibet aliquan similitudinem inter plantas fossiles, eum Comptonia ulmifolia, Quercu tenerrima, denticulata et plurinervia Wcb. sed ab iis diversum omnino est. Videtur potius simillimun Ulmo longifolice Ung., a qua tamen differt ob multo minorem magnitudinem.

\section{Ulmus gypsacea Massal.}

U. Foliis ovatis petiolulatis serratis penninerviis, basi inæqualitcr limbatis, eosta valida, nervis oppositis alternisve parallelis inæquidistantibus (2. 3 mill.) sub angulo aeuto egredientibus, simplicibus, apiceque tantum ramosis.

Syn.-Evonimus europaeus. Biacon., loe. cit., pag. 387, tab. XII, fig.3. - Ann. delle Sc. Nat. di Bol., T. I, 1838.

Abit. In gypso margaceo Forilivii Italix.

Observ. Hoe folium relatum a prof. Bianconi ad genus Evonimus, pertinet absque dubio ad Ulmaeeas, et longum est unum pollicem eum dimidio circiter, latum unum. Nervi sunt parallcli, simpliees, et parce ramosi tantum marginem versus. Quum pars superior hujus phillitidis fraeta sit, statui certe nequit ejus forma, basis autem incolumis est, prædita brevissimo petiolo inæqualibus oris laminæ, ornato.

\section{ARTOCARPE $\boldsymbol{A}$}

ARTOCARPIDIUM UNG

Artocarpidium integrifolium Ung.

Tab. nost. 111, fig. 8.

A. Foliis ovatis (acuminatis?) integerrimis penninerviis, nervo medio crasso, nervis seeundariis subremotis apicibus arcuatin conjunctis. Ung. Fl. v. Sot- 
$z k a$, pag. 36 (166), tab. 14 (35), fig. 3-4. - Massal., Piant. foss. del Vicent., pag. 142.

Abit. In gypso margaceo ad Senogalliam, nec non in schisto margaceo ad Chiavon agri Vicentini, Italiæ, et Sotzka Stiriæ.

Observ. Ileum fragınentum aliquanto perfectius est, quan depictum a P. Ungerio: ab eoque qui judicet, statuit apieem folii potius quam aeutum ut docuit idem professor, esse obtusum. Quum tamen et mea et Ungerii exemplaria aliquam partcm desiderent, characteres hujus folii incerti adhue evadunt.

\section{BA LSAMIFLUA.}

L.IQUIDAMBAR $L I N N$.

Liquidambar affine Massal.

Tab. nost. III, fig. s.

L. Foliis palmato-subquinquelobis subintegcrrimis, basi cordatis, lobis inferioribus brevissimis rotundatis horizontalibus, mediis obtusis erectis ovatis, terminalem late ovato-rotundatum subrepandum, aquantibus : nervis primariis validis, secundariis ramosis, areuatis, oppositis, alternisve.

Abit. In stagnigeno gypso ad Senogallian Italiæ.

Observ. Accedit proxime hæc species ad Acer vitifolium A. Braun. et Obtusilobum. Ung., Ch. Prot., tab. 43, fig. 10-12) si lobi mei exemplaris minus essent divaricati, nec quinque fere numerarentur, et præferrent alium nervorum ordinem.

Longa est plus quam pollicem eum dimidio, lata fere duos, valde cordata, cum costis admodum eonspicuis, et nèvis irregularibus alternisque.

\section{Liquidambar Tyberina Massal.}

Tab. nosı. 11, fig. e.

L. Foliis petiolatis palmato-trilobis triplincrviis, basi cordatis, lobis lateralibus ovatis obtusis adscendentibus integerrimis, terminali lancelato-acuminato duplo brevioribus: nervis primariis tenuibus, secundariis subobsoletis (Procace. Anat. Fill., Ann. delle Scienze. Nat. di Bol., 1838, T. II, tab. II, fig. 2.)

A bit. Cum priore.

Observ. Similitudinem magnam lıabet hxe species cum Acero Parschlugiano et pseudocampestri Ung. (Clil. Prot., tab. 43, fig. 5-6), sed ab ipso differt ob formam loborum et integritatem marginum, qui sunt crenati in speciebus Ungerianis. Folium mex speciei longum est unum pollicem et tres lineas circiter, et tantumdem latun, eum lobis prælongis, et usque ad basim leviviter sinuatam, divisis. E nervis tres tantum medii conspieiuntur, latcralium exigua indicia. 
Liquidambar Scarabellianum Massal.

Tab. nost. 11, fig. 1 .

L. Foliis palmato-quinquelobis intcgerrimis, basi late truneatis quinquenerviis, lobis inferioribus brevissimis rotundatis horizontalibus, mediis lanceolatis erectis acutis, terminali ovato-lanceolato subæqualibus. Nervis primariis validis, secundariis i emotis simplicibus alternis.

Abit. Cum prioribus.

observ. Folium palmato-quinquelobum, ad basim recte truncatum, congruc petiolatum, longum unum pollicem et 8 lineas, et latum ad basim unum circiter pollicem cum dimidio; lobis acutis et lanceolatis, quorum tres medii sunt distinctissimi; longus est quisque unum pollicem, inferiores parum distinguuntur et efficiunt angulum rectum cum limbo, petiolum versus. Nervi præcipui quinque numerantur, quorum tres medii sunt validiores, et offerunt vestigia alternorum et exilium nervorum lateralium. Margo totius folii est integerrimus. Dicatum amicissimo Scarabelli claris. geologo Foro-Corneliensi.

\section{Liquidambar Italica Massal.}

L. Foliis hastato-subquimquelobis quimquenerviis, basi profunde cordatis, lobis triangularibus subintegerrimis, inferioribus brevioribus deflexis, mediis patentibus, supremum latiusculum subæquantibus, nervis primariis distinctis flexuosis, secundariis alternis tenuibus ramosis.

Syn. - Acer campestre Procacc. Ann. delle Sc. Nat. di Bol., 1838, T. I, tab. V, fig. 4, pag. 212 , n: 70.

Abit. Cum prioribus.

Observ. Accedit hæc species ad meum Liquidambar affine, sed differt ob majorem loborum divaricationem, et ob æquam longitudinem, et ob formam, et præterea ob nervos et basim multo magis cordatam. Longa est unum circiter pollicem, et lata plus quam luos. Nervi distinctiores sunt tres nedii, duo reliqui vix videntur, et omnes flexuosi tenues et ramosiusculi.

\section{SA L I C I N E A.}

POPULUS TOURN.

Populus Phœtonis Viv.

P. Foliis cordatis abbreviato-ovatis acutiusculis quinquenerviis, marginc obsolete erenulato, nervis seeundariis basilaribus arcuato-adseendentibus alterne ramosis, nervo primario minoribus. - Viv., Mém. Soc. Géol. de Fran. T. I, pag. 133, tab. X, fig. 2. - Ung., Gen. et Sp. pl. foss., p. 418. 
Abit. In stagnigeno gypso ad Stradellam prope Papiam Italiæ.

observ. Folium longum plusquam unum polliccm, et latum tantundem, leviter cordatum et præditum quinque nervis ramosis prædistinctis ; petiolum deest, et videtur margine integro fuisse.

\section{Populus Bianconii Massal.}

P. Foliis petiolatis cordato-trilobis quinquencrviis, margine integerrimis, lobis lateralibus brevissimis cuspidatis, medio ovato maximo, nervis primariis conspicuis, nervis lateralibus crebris alternis oppositisque ramosis.

Syn. - Populus alba Biancon loc. cit. Ann. delle Sc. Nat. di Bol.1838, p. 388, tab. 13, fig. 2, vol. I.

Abit. In argilla ad Senogalliam.

Observ. Folium longum duos circiter pollices, et latum duos ejusque tertian partem, congrue pctiolatum, tribus lobis, quorum latcrales sunt exigui et acuti, mcdius deest, nec potest conijci quam longus esset et cujus formæ. "Nervi ejus palmares longitudine et crassitic longe inæquales; me" dius longior crassior, basi valde crassus obtusus apicc depressus subn occultus ramosus, ramis 4-5 inæquidistantibus flexuosis ramulosis, laterales primi aperti, paulo curvati impari-ramosi, ramis externis 4-5 " irregulariter flexuosis ramulosis, lateralcs sccundi minimi vix antrorsum " conversi, ramulis suboccultis 3-4, nonnullis occultis" (Bianc. loc. cit.) Inter fossiles species accedit proxime Populo leucophylla Ung.

\section{SALIX TOURN.}

\section{Salix latifolia Massal.}

S. Foliis lanceolatis acuminatis integerrimis penninerviis, nervo primario valido, nervis secundariis sub angulo $45-60^{\circ}$ orientibus, 5-8 mill. inter se remotis, subrectis simplicibusque:

Syn. - Salix ..... viv. (pro parte) Mem., loc. cit., tab. X, fig. 4. - Ung. Gen. et spec., pag. 419, ex parte.

Abit. In gypso stagnigeno ad Stradellam propc Papiam Italiæ.

Obser. Incertum mihi est cui classi tribuam hanc speciem. Refcro ad genus Salix, habet cnin magnam similitudinem cum foliis hujus generis. Acccdit proxime ad Cupanoides myocenicus Etting. ct ad Salicem grandifoliam Wcb., sed differt ob formam nervorum.

\section{Salix Vivianii Massal.}

S. Foliis linearibus lanccolatis ubtusiusculis integerrimis, nervo primario distincto, nervis secundariis oppositis $\mathbf{v}$. alternis parallclis simplicibus adscendentibus. 
Syn. - Salix ..... . Viv. (pro partc) loc. cit. tab. XI, fig. 8 (et 9?) - Ung. loc. cit. (ex parte).

Abit. Cum priore.

Observ. Itidem incertum est, an hujusmodi imago eollocanda sit sub genere Salix, attamen non subscribo clar. Vivianio, fig. 8-9 (tab. XI) et 4 (tab. X) sui operis, spectare posse ad unum et eundem vegetalein.

\section{LAURINEA.}

LAURUS LINN.

\section{Laurus obovata Web.}

L. Foliis petiolatis oblongis obovato-acuminatis integerrimis, basi attenuatis, nervo primario sensim decrescente, secundariis vix conspicuis, irregolaribus arcuatis. Web. die Tertiar. Fl. der Nied. tab. III, fig. 4, pag. 66. Procacc. Ricci. Ann. delle Scien. Nat. di Bolog., vol. II, 1838, pag. 17, N. 1, tab. I, fig. I.

Abit. In stagnigeno gypso ad Senogalliam Italiæ, nec non in arenaceo ad Quegstein prope Bonnam.

Observ. Figura hujus speciei a Procaccinio-Riccio exhibita loco citato, quamvis inperfecta, convenit tamen adeo cum specie Lauri delincatæ a Webero, ut non dubitem cum illa comparare. Fortasse fig. 2 ejusd. tabulæ Procaccinii unum ac idem erit?

DAPIINOGENE UNG.

\section{Daphnogene paradisiaca Ung.}

Tab. nost. 111, fig. 6.

D. Foliis subcoriaceis petiolatis e basi æquali parum angustata ovato-oblongis acuminatis (remote obtuse dentatis), triplincrviis, nervis secundariis basilaribus simplicissimis curvatis, retc venoso tenuissime exculpto. - Ung., Gen. et spec., pag. 424 . - Fl. v. Sotzka, pag. 37 (167), tab. 16 (37), fig. 8-11 et tab. 17 (38), fig. 1-7. - Viv. Mem. Soc. Géol., loc. cit., tab. 9, fig. 4.

Abit. In gypso stagnigeno ad Senogalliam et ad Stradellam prope Papiam, ill schisto calcarco ad $M$. Bolca Italiæ, nec non ad Rodobojum Croatiæ et Sotzka Stirix.

Observ. Meum exemplar, quod est procul dubio species Cl. Prof. Ungeri, nullum exhibet dentium vestigium ad margines, quos habet integerrimos: id tamen determinationi meæ nullo modo obest, auctor enim ipse folia hujus speciei marginibus integris depixit in Flora Sotzkana. Præterca in meo typo nullum conspicitur indicium retis venosi. Folium hoc pergamenacea 
mehercule eonsistentia et natura fuit, reliquit enim præeonspicuam in lapide imaginem. - Daphnogene Paradisiaca pertinet eerte ad Floram Eocenicam et Miocenicam.

\section{Daplenogene cinnamomeifolia Ung.?}

D. Foliis coriaeeis petiolatis e basi æquali ovalibus oblongis obtusis v. aeuminatis margine integerrimis triplinerviis, ncrvis secundariis supra-basilaribus. - Ung., Gen. et sp., 424. - Syn., pag. 217. - Fl. v. Sotzka, tab. 18 (38), fig. 7-y.

Syn.? - Phillites cinnamomeifolia Brong. Prodr., pag. 209. - Phyllites cinnamomeus Rossm. Beit. 2, Verst. 1, pag. 23, tab. 1, fig. 1-8. - Viv. Mem. Soc. Géol., loc. cit., tab. XI, fig. 2 (?)

Abit. In stagnigeno gypso ad Stradellam prope Papiam Italiæ, in schisto margaeeo ad Stradellam Croatiæ ad OEningen et Parschlug, nec non in arenaeeo lignitum ad Altsattel Bohemix.

observ. In dubio versor in referenda hae phyllitide, a Vivianio depieta, ad Daphnogenem Cinnamomeifoliam Ung., namque mihi videtur potius eonvenire eum Ceanotho subrotundo Alx. Br. Idque solum facio ut opinionem ampleetar clar. prof. Unger qui eam retulit in sua opera Genera et species ad Dophnogenem cinnamomeifoliam.

\section{APOCYNEA.}

APOCYNOPIIYLLUM UNG;

Apocynophyllum Russegeri Etting.

Tab. nost. IV, fig. 4.

A. Foliis brevissime petiolatis v. sessilibus lanceolatis vel lineari-laneeolatis aeuminatis basi angustatis integerrimis sub-coriaccis, nervo primario distincto, nervis secundariis sub angulo $45-60^{\circ}$ orientibus, areuatis, 6-8 mill. inter se remotis. Etting., fossil. pflanz. aus den Trachitisch., pag. 9, tab. 2, fig. 4-6.

Abit. In gypso margaceo ad Senogalliam Italiæ, nec non in arenaceo traelıytico ad Heiligenkreuz prope Kremnitz.

Observ. Meum exemplar multo majus est imaginibus ab Ettingshauseo depictis, eisque multo perfectius, tamen puto unum ideñque esse quamvis similitudinem exhibeat eum aliis speciebus fossilibus. - Dubito potius de ejus eolloeatione inter Apocyneas, quum videam multas plantas ex ordine $R u$ biacearum, gerere folia huic phyllitidi simillima. 


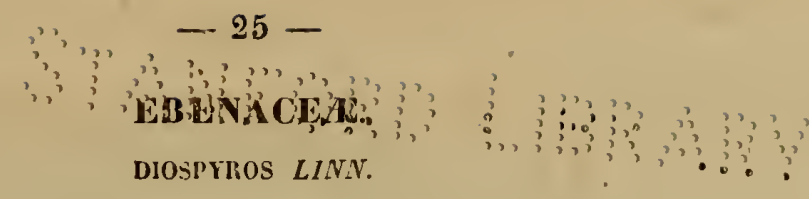

Diospyros pannonica Eltings.

E. Foliis elliptieis bası angustioribus, integerrimis, petiolatis, nervis seeundariis undulatis sub angulo $50-60 .^{\circ}$ orientibus, apice ramosis et in rete abcuntibus. Ettings. Foss. Fl.v. Wien, pag. 19, tab. 3, fig. 8. - Saví, Carb. foss. delle Marem., loe. cit., tab. II, fig. 9.

Abit. In schisto caleareo phœtido ad M. Bamboli taliæ, nee non in ealcareo ad Vindobonam.

Obser. Si imago hujus folii a prof. Savio depicta, perfeeta sit, ipsa adamussin congruit cum, superius descripta specie. Aliæ plures imágines in eadem 1I. ${ }^{a}$ tabula depinguntur a prof. Savio, sed eædem sunt nimis imperfectæ, ut eas determinare possimus. Ex ipsis figuræ 4-7 aecedunt ad Bombax Sagorianus Etting., 13 autem esse posset Dophnogene quædam, 6 et 8 fragmentum fortasse Tcrminalia miocenice Web., 11 fortasse Rhamnus Deckenii Web., 2 videtur absque ulla dubitatione Alnus gracilis Ung.

\section{ERICACE}

ANDROMEDA LINN.

Andromeda? Senogalliensis Massal.

Tab. nost. IV, fig. 3.

A. Foliis oblongo-obovatis obsolete repandis obtusis retusisve, petiolo lamina sua sextuplo v. octuplo breviore, costa valida, nervis simplicibus tenuibus arcuato-adscendentibus inæquidisıantibus alternis. -- Procaec. Ricc., Ann. delle Scienz: Nat. Bolog., T. I, 1838, tab. IV, fig. I, pag. 195, N. 1. Abit. In gypso margaceo ad Senogalliam Italiæ.

Observ. Vigentium plantarum folia complura eum hae planta fossili eonferri possent, ejusque determinationem dirigere. - Mihi vero nulli alii generi adseribenda consultius videtur, quam generi Andromeda, cujus speeiebus similis magnopere apparet. Inter specics fossiles, cognitas, forma aliqua Pyri Troglodytarum, Rhododendri Uranio, Mirice deperditce, Quercus lignitum, Rhamni Eridani analogiam quamdam exhibct, non tamen ita ut ulla harum specierum possit eum ea eonfundi.

\section{Andromeda? incerta Massal.}

Tab. nost. IV, fig. I.

A. Foliis oblongis integris obtusis, basi attenuatis, petiolo laminæ dimidium æquante, eosta crassiuscula, nervis oppositis alternisve parallelis, sub angulo $45^{\circ}$ egredientibus, areuatim eonjunetis 5-8 mill. inter se remotis. 
Abit. Cum priore.

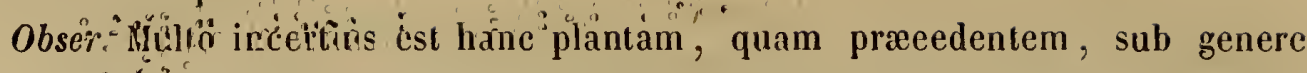
Anăromeda collocare, nec video, cui alii generi sit potiori jure tribucnda.

Pyrus Troglodytarum, Laurus lalages inter species fossiles prope accedunt, sed characteres omnes non conveniunt.

VACCiNiUM LINN.

Vaccinium Acheronticum Ung.

Tab. nost. 11, fig. 8.

V. Foliisovato-lanceolatis obtusiusculis integerrimis petiolatis subcoriaceis, nervo medio distincto, nervis sccundariis subtilibus ramosisve. - Ung., Gen. et sp., pag. 440. - Fl. von Sotzka, pag. 173, tab. 45, fig. 1-17. Massal., Piant. foss. del Vicent., pag. 151.

Abit. In gypso margaceo ad Senogalliam, in schisto margaceo ad Salcedo et Chiavon agri Vicentini Italia, nec non ad Sotzka Stiriæ et Radobojum Croatiæ.

Observ. Convenit omnino meum exenplar cum diagrammatibus 5 et $\$ 5$, tab. 26. Flora Sotzkance quæ exhibent folia juniora Vaccinii Acherontici Ung. Folia hujus specici pollicis et pollicis cum dimidio longitudinem attigunt, latitudincm medii pollicis et 3-4 lincas. Exemplar parvum Senogalliense quod describo, longum est paulo plus medio pollice, latum lineas tres, petiolo brevi, indieiisque vix sensibilibus nervorum lateralium. Inter species Vaccinii vigentes accedit ad folia V. Tenelli Ait. Orientalis, hispiduli Ait., macrocarpi, oxicocci, obtusi, alaternoidis; differt tamen vel ob majorem minorcmve magnitudinem, vel ob apicem plus minusve obtusum.

\section{CORYEA.}

CORNUS TOURN.

Cornus? ambigua Masśal.

Cor. Foliis oblongis integris brevissimc petiolatis penninerviis, apice subacutis, costa conspicua, nervis parallelis simplicibus. - Viv., Mem. Soc. Géol., loc. cit., tab. X, fig. 5.

Abit. In gypso stagnigeno ad Stradellam prope Papiam Italiæ.

Observ. Vivianius ne verbum quidem profert de hac pliyllitide, ipsa tamen quam maxime congruit cum Sapindaceis et Corneis, et mea quidem sententia eum his magis quam cum illis. 
 \\ MAGNoLIACEL. \\ LIRIODFNDRON LINN.}

\section{Liriodendron Procaccini Ung.}

L. Foliis trilobis, lobo medio maximo truncato-emarginato, lobis lateralibus oblusis v. acutis integerrimis, nervis secundariis pinnatis sub simplicibus. -- Ung., Gen. et sp., pag. 443. - Procace., Progress. delle Seienz. Nap. XI, 1825, fig. 41, 66, 70, 121.

Abil. In gypsorum stratis ad $S$. Angelo et $S$. Gaudenzio prope Senogalliam Italix.

\section{STERCULIACER.}

STERCULIA LINN.

\section{Sterculia acerites Massal.}

Tab. nost. 1, tig. 4.

s. Foliis petiolatis cordato-subrotundis integerrimis quinquenerviis, apice trilobis, lobis lateralibus acuminatis, lobo medio ovato-acuto brevioribus, nervis primariis conspicuis, inferioribus curvatis, nervis secundariis altcrnis inæqualibus ramosis.

Abit. In schisto margaceo ad Senogalliam Italiæ.

Observ. Folium cordato-trilobum, lobis acutis et integerrimis, longum tres pollices, latum duos cum dimidio si totum superesset, quinque nervis præcipuis e quibus laterales obliquiores, et in arcum vergentes, præditi ad latera plurimis et alternis iisque ramosis venis, sub angulo acuto orientibus. - Collocassem libenter hoc folium inter Acerites, offert enim similitudines non exiguas cum speciebus hujus generis: magis tamen placet referre ad Sterculiaceas ut cum cl. prof. Ungero conveniam. Inter species fossiles accedit ad Acerum vitifolium A. Br. et dubium Web. sed differt ob margines integros.

\section{ACERINEE.}

ACERTES $V I V$.

Acerites ficifolius Viv.

Tab. nosı. 1, fig. 1.

A. Foliis longe petiolatis magnis subcordato-trilobis, lobis obtusis sinuato-dentatis, medio productiore subtrilobo, nervis secundariis pinnatis, infimis maximis. Ung., Gen. et sp., pag. 452. - Viv., M $\mathrm{cm}$. Soc. Géol. de Franc., 1833, 1, pag. 131, tab. 9 , fig. 5.

Abit. In stagnigeno gypso ad Stradellam prope Papiam, nec non ad Senogallicm Italiæ, et Freiberg Stiriæ. 
Observ. Folium Jongum plus quarn tres polices cum dimidio, petiolo non comprekensón 'átum quatuor circiter cum dimidio, forma cordato-triloba, lobis obtusioribus sinuato-dentatis, quorum medius, folium medium exæquat longitudine. Petiolus in meo exemplari quamvis abscissus, longior est pollice et tertia parte, et paulo latior millimetro, duobus autem ad basim, unde exeunt nervi tres præcipui, qui medium sccant quemque, lobum, et ad latera millores gerunt ncrvos, semper alternos et fere parallclos. Nervi laterales habent ad latera 9-10 nervos minores, e quibus qui sunt ad basim validiores, qui ad apicem tenuiores et frequentiores.

Venæ inter se fere parallelæ ct ut nervi minores nascuntur sub angulo 65-70 graduum, ad apicem dividuntur et conjunguntur venis superiorum nervorum. - Impressio levis foliorum, contra nervorum et petioli, impressio conspicua : quo patet validis admodum nervis, et natura membranacca hanc speciem fuisse. - Inter specics vigentes congruit cum Acero platanoide.

\section{Acerites integerrimus Viv.}

Tab. nost. 1, fig. 3 .

A. Foliis basi cordatis palmato-quinquclobis, lobis lanceolatis acutis integerrimis. Ung., loc. cit. - Viv., loc. cit., tab. 11, fig. 6.

Syn. - Acer campestre Bianconi? Syst. vasc. delle Fill., Ann. di Bologn., pag. 387 , tab. 13 , fig. 1 ?

Abit. In stagnigeno gypso ad Stradellam prope Papiam, ad Senogalliam Italiæ, nec non ad Freiberg Stiriæ et Swosrowice Galiciæ.

Observ. Folium cordatum palmato-quinquelobum, longum tres pollices, et tertiam partem, latum tantundem, lobis lanceolato-acutis, nervi præcipui omnes prædistincti, - laterales exigui arcuato-ascendentes, indicio venarum nullo. E spcciebus vigentibus accedit proxime ad Aceres dasicarpa et rubra. Prætermittere tamen nequco ejus analogiam cum foliis Sterculiacearum et Balsamifluearum, et inter catera cum speciebus generis Liquidambar. Simillima' est hæc Vivianii specics cum Sterculia Vindobonensi Etting. vel potius Liquidambar, quæ differt nulla alia de causa, quam quod habet basim multo magis cordatam, ncrvos sccundarios frequentiores, et lobos fortasse breviores ac obtusiores.

\section{Acerites elongatus Viv.}

A. Foliis oblongis trilobis integerrimis, lobo medio maximo, lobis lateralibus patcntibus, nervis pinnatis inlimis maximis. - Ung., Gen. et sp., pag. 452. - Viv., loc. cit., tab: 10 , fig. 3 . 
Abit. In stagnigeno gypso ad Stradcllam prope Papiam Italix.

Observ. Folium plus' quam 4 pollices longum, tres vero latum, forma irregulariter triloba, lobisque lateralibus vix distinctis, et medio magno, diInidiam folii longitudinem superante. - Costa est valida, nervi simpliees alterni, et sub angulo $35-40^{\circ}$ c eosta egredientes. Margo totius folii integerrimus. Inter specics viventes convenit eum Acero cretico Linn.

$$
\text { ACER MÖNCH. }
$$

Accr productum A. Braun.

A. Foliis petiolatis basi truneatis palmato-trilobis inciso-dentatis acuminatis, lobo medio productissimo, samaræ magnæ ala cxtensa, margine inferiore rotundato. - Ung., Gen. et sp., pag. 451. - A. Braun. Neus. Jharb., 1845, pag. 172. - Ung. elıl. prot. pag. 131, tab. 41, fig. 1-9. - Massal., Piant. foss. Vicent., pag. 188. - Viv., loc. cit., tab. XI, fig. 5.

Abit. In stagnigeno gypso ad Stradcllam prope Papiam, in sehisto margaeeo ad Salcedo ct Chiavon agri Vicentini Italiæ, nce non in terra lignitum ad Oeningen, Bilinum, Parschlug et Arnfels.

observ. Convenit omnino hæe imago a Vivianio depieta eum figura 2, tab. 42 Chloris Protogcee. - Inter plantas viventes eongruit cum Acero dasycarpo.

\section{Acer integrilobum Web.}

A. Foliis palmato-trilobis basi rotundatis v. subcordatis integris vel subintegris, lobis longe aeuminatis, medio produeto; sinubus acutis. - Web. die Tertiär. Flora der Nieder., pag. 82, tab. 5, fig. 5.

Syn. - Acer monspessulanum Viv., Mem. Soc. Géol., loe. eit., tab.10, fig. , pag. 130. (Ung., Gen. ct sp., pag. 449 ).

Abit. In stagnigeno gypso ad Stradellam prope Papiam Italiæ, nec non in terra lignitum ad Stosschen ad Rott., in arenaceo ad Quegstein prope Bonnm.

Observ. Professor Ungerius retulit dubitans hane imaginem a Vivianio depictam, ad ejus Acerum pseudomonspessulanum (Chl. prot., tab. 42, fig. 1-4). - Ego tamen arbitror referendam esse ad superius descriptam a Webero speciem, nisi et ipsa referenda sit ad spceiem ipsam Ungerianam, sive ad ejus Acerum Sotzkianum. 


\section{MALPIGHIACE E. \\ MALPIGHIASTRUM UNG. \\ Malpighiastrum lanceolatum Ung. \\ Tab. nost. Il, fig. 12.}

M. Foliis laneeolatis aeuminatis petiolatis integerrimis subcoriaceis, nervis secundariis majoribus eum minoribus alternantibus. Ung., Fl. v. Sotzka, tab. 29 (50), fig. 6-7, pag. 46 (176). - Web., loc. cit., tab. V, fig. 7.

Abit. In gypso stagnigeno ad Senogalliam Italiæ, nec non informatione cocenica ad Sotzka Stiriæ et Rodobojum Croatiæ.

Observ. Rhamnus Dechenii Web. foliolumque aliquod Cassice phaseolitidis Ung. Palcoolobii heterophylli. Ung. Celastri elceni Ung. et nonnullum etiam foliolum Glycirrhizze deperdita Ung., cum folio de quo dissero congruere aliqua ex parte videntur. Nullum tamen cum eo ita convenit ut fig. 6 , tab. 29 , flor. Sotk., ideoque illi speciei nullo metu adscribo.

\section{ILICINE $\boldsymbol{E}$.}

ILEX LINN.

Ilex Stenophylla Ung.

Tub. nost. 11, fig. 6, et lab. IV, fig. 11.

I. Foliis breviter petiolatis lineari-lanceolatis obtusis, margine subrevolutis, costa media notatis. Ung., Gen. et Sp., pag. 461. - Chl. Prot., pag. 149, tab. 50, fig. 10-11. - Procace. Rice. Anat. Fill. Senog., Ann. di Bol. 1838, T. II, tab. 2 , fig. 4.

Abit. In gypso stagnigeno ad Senogalliam Italiæ, nec non ad Radobojum Croatiæ.

Observ. Folium longum paulo plus quam pollicem, latum 4 ad 6 lineas, forma lanceolato-obtusa, nervo tantum medio distineto, et petiolo prævalido. Inter species vigentes accedit ad Ilicem angustifoliam Americæ septentrionalis.

\section{RHAMINEA.}

CEANOTHUS LINN.

Ceanothus subrotundus A. Braun.

Tab. nost. 11, fig. 9.

C. Foliis suborbicularibus $\mathbf{v}$. obovatis acuminatis basi rotundatis $\mathrm{v}$. in petiolum attenuatis, integerrimis triplinerviis, nervis secundariis infimis subbasilaribus extrorsum ramosis, reliquis subsimplicibus. - Ung., Gen. et Sp., 
pag. 665-66. - Chl. Protog., p. 144, tab. 4, fig. 7. - IVeb., loe. cit. tab. 6 , fig. 6 .

Abit. In gypso stagnigeno ad Senogalliam Italix, in schisto margaceo ad Parschlung Stiriæ, ad Oeningen Magnidueatus Badensis, nec non ad Rodobojım Croatiæ.

Observ. Folium hujus speciei longum est fere duos pollices, latum vix unum, servaturn est felieiter, distinctos habet nervum medium, et duos laterales, qui prope basim ineipiunt et ad latera gerunt venas alternas, quæ nascuntur sub angulo recto et ad apicem sejunguntur.

\section{COMB R E T A C EAE.}

GETONIA ROXB.

\section{Getonia Oeningensis Ung?}

- Tab. nost. IV, fig. 12.

G. Calicis limbo persistente, eampanulato, membranaceo, quadrifido, lacinis ovatis plurinerviis, nervis retieulatis. Ung., Gen. et Sp. pl. foss., pag. 478. Web., Tertiär. Flor. der Nied., tab. 7, fig. 2.

Syn. - Antholitus Oeningensis Al. Braun. Mansc. - Viburnum Oeningense König. Icon. foss. Sect. - Cordia tilicefolia A. Braun Ncus. Ihrb. für Min., 1845, pag. 170 .

Abit. In gypso stagnigeno ad Senogalliam Italiæ, nec non in schisto margaeeo ad Oeningen et in terra lignitum ad Orsberg prope Bonnam.

Observ. Inccrtus aliquandiu fui, ad quam speeiem referenda hæc planta esset. Videbatur quippe nova aliqua Getonice speeies, potius quam Getonia Oningensis Ung, differt enim hoc fragmentum, quod aliquanto majus et minus obtusum est. Forma tamen et venarum dipositione convenit omnino.

\section{P O M A EAL.}

PYRUS LINN.

Pyrus Troglodytarum Ung.

Tab. nost. 1I, fig. 5.

P. Foliis petiolatis ovato-oblongis bi-tri-quadri-polliearibus obtusis integerrimis penninerviis, sæpius deformibus, nervo primario valido, nervis seeundariis simplicibus curvatis alternis. Ung., Gen. et Sp., pag. 481. - Fl. v. Sotzk, tab. 58, fig. 1-10. - Massal. Piant. foss. del Vicent., pag. 205.

Abit. In gypso stagnigeno ad Senogalliam, in calcareo margaceo ad Chiavon agri Vicentini Italiæ, nee non ad Trofeiuch et Rodobojum Croatiæ.

observ. Ad nullam æquius speeiem referendam plantam arbitror, quam ad 
Pyrum Troglodytarum Ung.: Rhamnus aizoon, Pyrus Euphemes et præcipue $P$. Theobroma ejusdem auctoris, multas cquidem magnasque cum ea similitudines habent: tamen carent eharacteribus quibus huic speciei typum Senogalliensem tribuamus. Nonnulla ex multis diagrammatibus a prof. Ungerio exhibitis Pyri Troglodylarum in Flora Sotzkana, et in primis fig. 9, tab. 58, eonvenit prope omnino cum meo exemplari.

\section{Papilionacere.}

LEGUMINOSITES BOH'ERB.

\section{Leguminosites Viviani Massal.}

L. Foliis ovato-laneeolatis acutis, basi rotundatis integerrimis, nervo primario valido, secundariis sparsis obsoletis.

Syn. - Coriaria myrtifolia Viv. Mem. Soe. Géol., loc. cit., tab. 11, fig. 3. Ung. Gen. et Spec. pl. foss., pag. 456.

Abit. In gypso stagnigeno ad Strallellam prope Papiam Italiæ.

Observ. Folium longum duos vel tres pollices circiter, latum vero a 9 lineis ad unum pollicem, forma laneeolato-aeutum, basique subrotundum: costa est valida, nervi tenues et alterni inter se valde distantes, simplices et sub angulo acuto orientes. Valde miror Vivianum perspexisse omnimodam similitudinem hujus folii eum Coriaria myrtifolia, et eo usque pervenisse, ut adfirmaret ita parem esse ac si super folia hujus speeiei depieta fuisset. Coriaria myrtifolia prabet folia triplinervia, nihilque commune habet cum speeie oppidi Strulella, quam folii nomen.

Leguminosites.Macheroilles Etting. ?

L. Foliis pinnatis, foliolis ovato-cllipticis integerrimis aeutis, enriaceis, basi subeordatis vel rotundis scssilibus, nervis secundariis tenuissimis, eurvatis (apiee sæpius ramosis et in rete tenerrimo resolutis) Etting., foss. $\mathrm{Fl}$. v. Wien., pag. 24, tab. 5, fig. 4. - Vivian., loc. eit., tab. 11, fig. 1 ?

Abit. In stagnigeno gypso ad Stralellam prope Papiam Italix, nee non in sehisto margacco ad Vindobonam.

Observ. Iale equidem depictum.cxemplar Vivianii, ut possit tuto statui ad quam speeiem revera pertineat: accedit tamen proẹl dubio ad speeicn supra descriptam, Euingshausii. - Suspicionem quamdam proferre debeo: differt ne hic typus Vivianii ab ejus Coriaria myrtifolia? Ilæc autem differt sine dubio a Legum. Machceroides el ingafolius Etting.? Aut quatuor omnes species sunt omnino unum?? 
PALAOLOHUM UNG.

Palcolobium Haringianum Ung.

Tab. nost. IV, fig. 7 , et tab. 11, fig. 7 .

P. Foliis lanceolatis apiculatis integerrimis, nervis secundariis plurimis simplicibus parallelis. - Ung., Gen. et Sp., pag. 490.-Fl. von Sotzk., tab. 41, fig. $8-10$, pag. 56 .

Abit. In gypso stagnigeno ad Senogalliam Italia, nec non in schisto margaceo ad Hcering Tirolis.

Observ. Nullum relinquit dubium plantæ hujus determinatio : convenit enim omnino cum specie Ungeriana. In meo exemplari folium est longum paulo plus pollice, latum 9-8 lineas, quoad fructum lujus speciei singularem, vide quæ scripsit cl. Unger, et quod nosmetipsi tradinus, loquentes de nostro Carpolite hyophorbioides, pag. 230 nostrarum Osservazioni sulle piante fossili del Vicentino. Padova, 1851. 


\section{NOT E.}

(') Opera de plantis fossilibus ab Italis hactenus edita, quœe ego noverim, sunt sequentia:

Vivian. Lettre à M. Pareto sur les restes de Plantes fossiles trouvés dans les gypses tertiaires de la Stradella près Pavie 7 pag., 3 tab. (Mémoires de la Soc. Géol. de France. T. I, 1. ${ }^{\text {er }}$ part., 1833 , n. vir. )

Procaccisi-Ricci. Lettera prima al prof. Ant. Alessandrini, sull'anatomia delle filliti Sinigagliesi, pag. 23, 2 tab. (Annal. di Bolog. Ann. I, tom. I, 1838, pag. 190.213, tav. Iv-v.)

Procaccini-Riccl. Lettera seconda al prof. Alessandrini sull' Anatomia delle filliti Sinigagliesi. pag. 22, tab. 2. (Annal. di Bolog., 1838, tom. Il, pag. 14-36, tav. 1-2.)

Procaccini-Riccr. Lettera terza al prof. Alessandrini sui vegetabili fossili delle colline Sinigagliesi. (Annali di Bolog., Ann. II, vol. IV, pag. 427-135.)

Procaccint-Ricci. Un cenno sul colore delle filliti Sinigagliesi. (Amal. di Bolog., Ann. III, tom. V, pag. 265-278.)

Procaccini-Ricci. Lettera al direttore del giornale intitolato Il Progresso delle Scienze, delle lettere e delle arti in Napoli. (Napoli, 1835, il Progresso, quader. XXII, p. 211, 218.)

Procaccinı-Ricci. Lettera al cav. Lodovico Bianchini sulle filliti Sinigagliesi. (Napoli, il Progresso, 1836, quader. XXX, pag. 202-206.)

Procaccivi-Rrccr. Lettera II al cav. Bianchini sulle filliti Sinigagliesi. (Napoli, 1837, quader. XXXIV, pag. 238-247.)

Procaccinı-Rıccı. Lettera IV, sui Filliti Sinigagliesi. (Il Progresso, N̦apoli, 1838, ann. 7, quader. 42, pag. 197-214.)

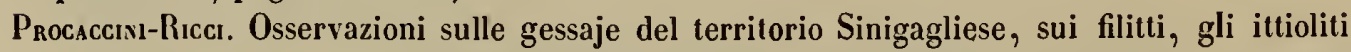
ed altri oggetti contenuti nelle medesime. (Roma, 1828, presso Vic. Poggioli, 8. ${ }^{\circ}, 102$ pag., $\mathbf{B}$ tab.)

G. Prof. Bianconı. Sistema vascolare delle foglie, considerato come carattere distintivo per la determinazione delle filliti (Annal. di Bolog., tom. I, 1838, pag. 343-390, 7 tab. lit.)

Massalongo. Schizzo geognostico sulla Valle del Progno o torrente d'Illasi, con un saggio sulla Flora primordiale del MI. Bolca (Proeludium Florce fossilis Bolcensis). Verona, 1850, $8^{\circ}, 78$ pag., tipogr. Antonelli.

Massalongo. Sopra le piante fossili dei terreni terziarii del Vicentino. Osservazioni etc. (Padova, tipogr. Bianchi, 1851, 8. $.^{\circ}, 264$ pag.)

Massalongo. Conspectus Floræ tertiariæ orbis primævi. (Patavii, typis An. Bianchi, 1852, 12." 37 pag.)

Massalongo. Synopsis palmarum fossilium (Prag., 1882, 18 pag., A us den Natur.-listorische Vereins sozos Febr.)

Massatongo. Sapindacearum fossilium Monographia (Veronæ, typis Ramanzinianis, 1852, 8. ${ }^{\circ}, 28$ pag., 6 tab. lithog.)

Massat.osco. Nota sopra due frutti fossili del bacino lignitico di Leffe (Ann. di Bologna, 7 ottobre, 1852,7 pag., tav. lilog.) 
Massalovgo. Breve rivista dei frutti fossili di Noce, e descrizione di due nuove specie ( $\mathrm{Kn}$. di Bologna, 1852, genn. e febbr., 1 tab. litog., 8 pag.)

Massalongo. Enumerazione delle piante fossili miocene fino ad ora conosciute in Italia (Verona, 1853, tipogr. Antonelli, $8 .^{\circ}, 32$ pag.)

Massatongo. De gramineis in statu fossili brevis commentatio (Ratisbonæ, 1883, Flora 7 mar., n. 9, pag. 129-153, cum 1 tab. litl.

Tonvabese D. F. Prof. Intorno ad alcune impronte di foglie e fusti vegetali che trovansi nella formszione dell'argilla presso Calania. 3 pag.

Hic dımıxat recensui auctores ltalos qui scripserunt de plantis fossilibus in peculiaribus operibus, ideoque silentio præterivi qui obiter tantum de iis in generalibus operibus tractaverunt. Si mihi opus esset commemorare eos qui majorem numerum descripserunt plantarum fossiliu m italarum, recensendi essent Savi et Meneghini (Mem. sulla Strat. Geol. delle Al. Vert. etc. Firenze, 1851), Parlatore (Leller al prof. Savi); Savi (Carb. Foss. delle M(trem.), Faujas Saint-Fond (Mémoires sur quelq. foss. rares de Vestena, etc. Annales du Mus., vol. 3, 1804), Rozan (Conjecture sur les plan. foss. de M. Bolct. Napoli, 1823), Brongniart A. (Prodromus, Histoire, Descripl. giol. des env. de Paris), Sternberg (Versuch, etc. Unger (Synopsis, Genera et species, Chloris Prot., Iconographia), Münster (Beiträge), Scheuchzer (horbar. Dilus.) etc. etc. etc. 


\section{Tirn. I.}

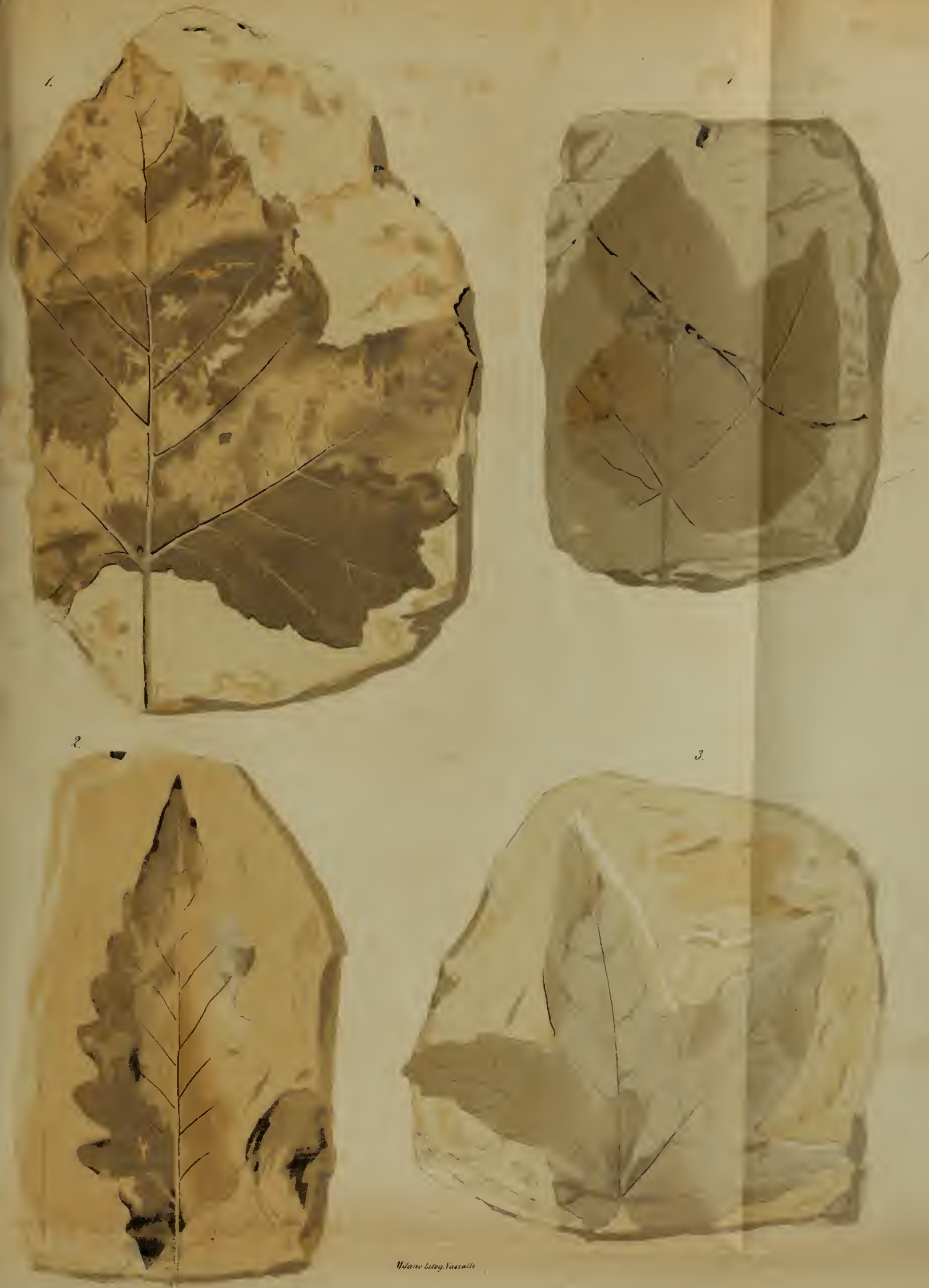

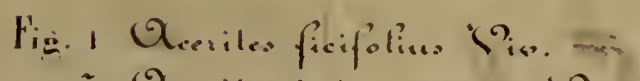

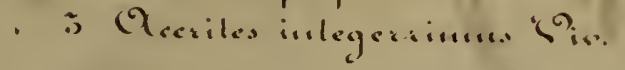

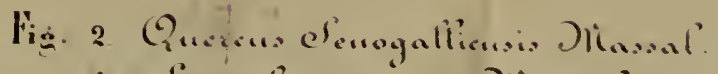

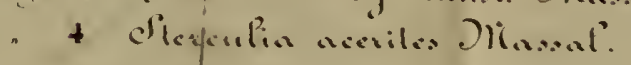


$\because !|n|$

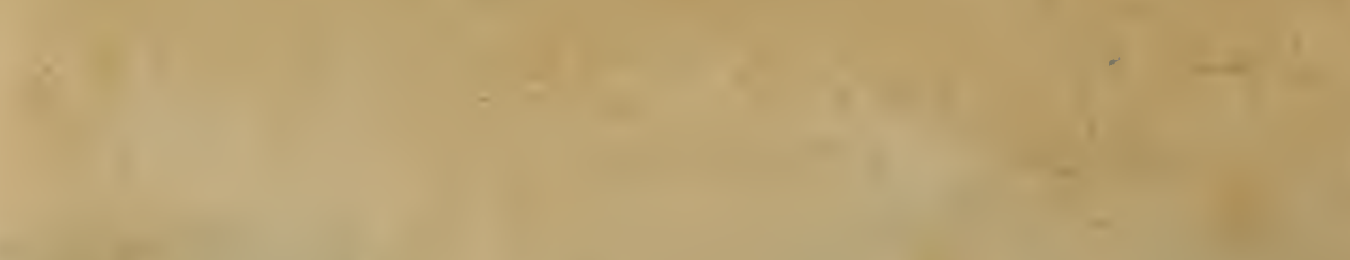
ta
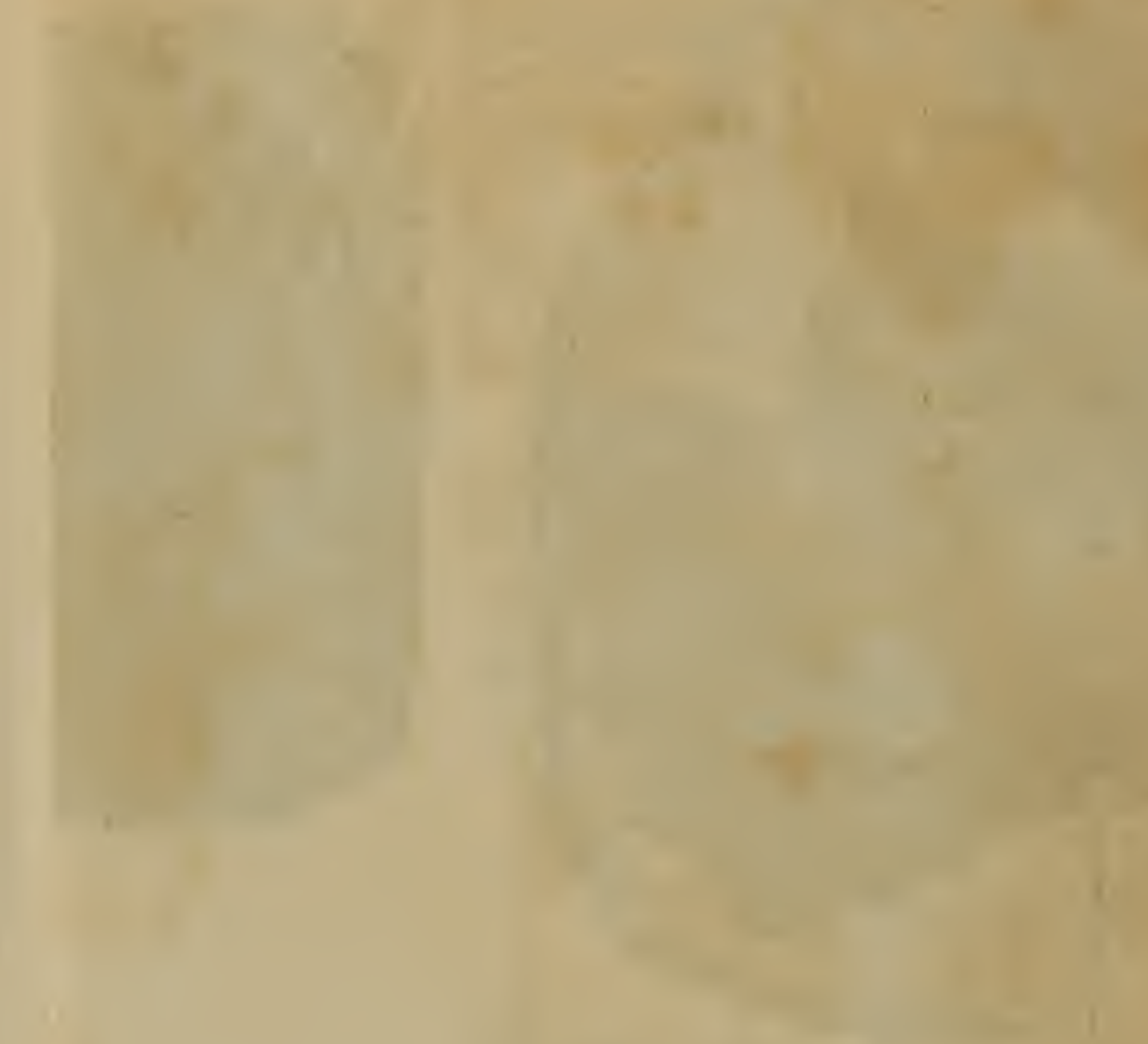

+
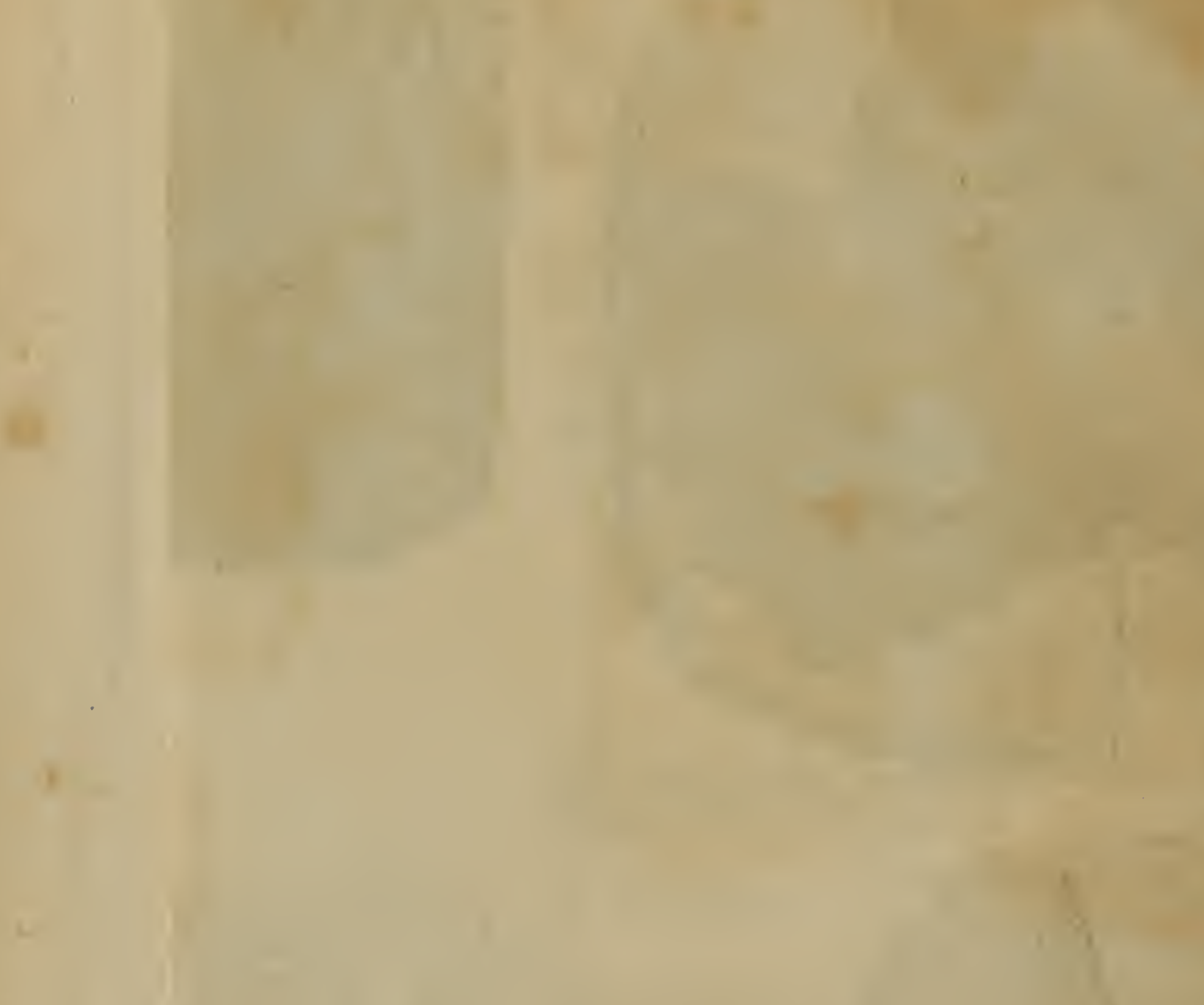


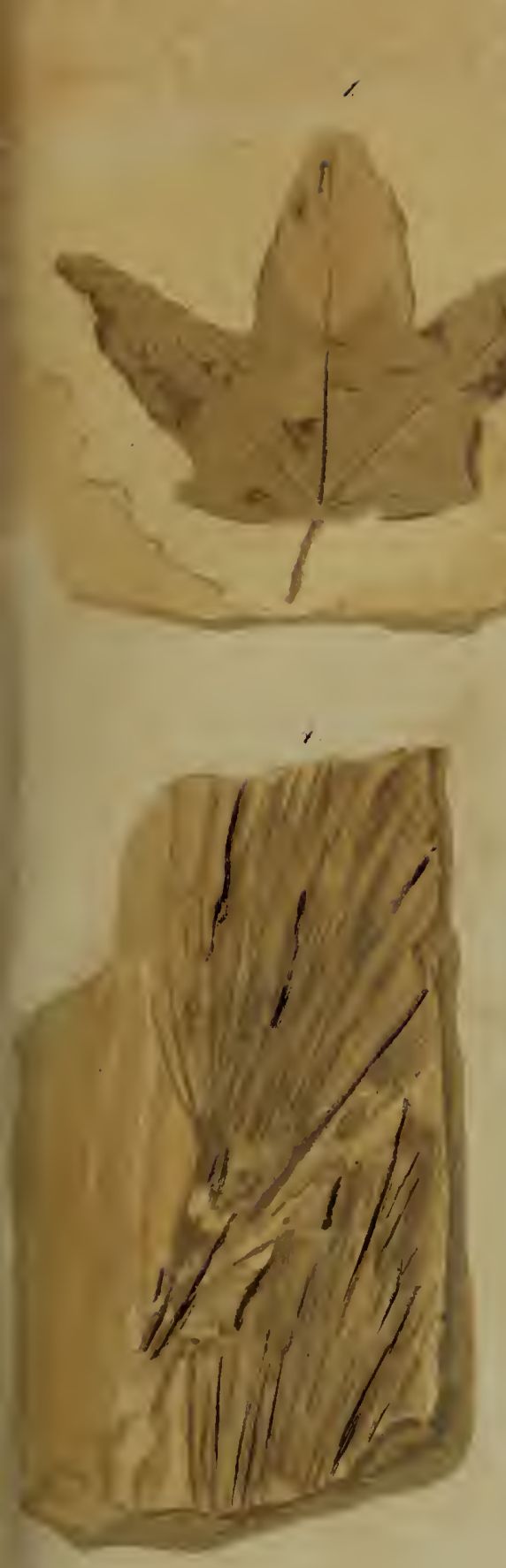

2.
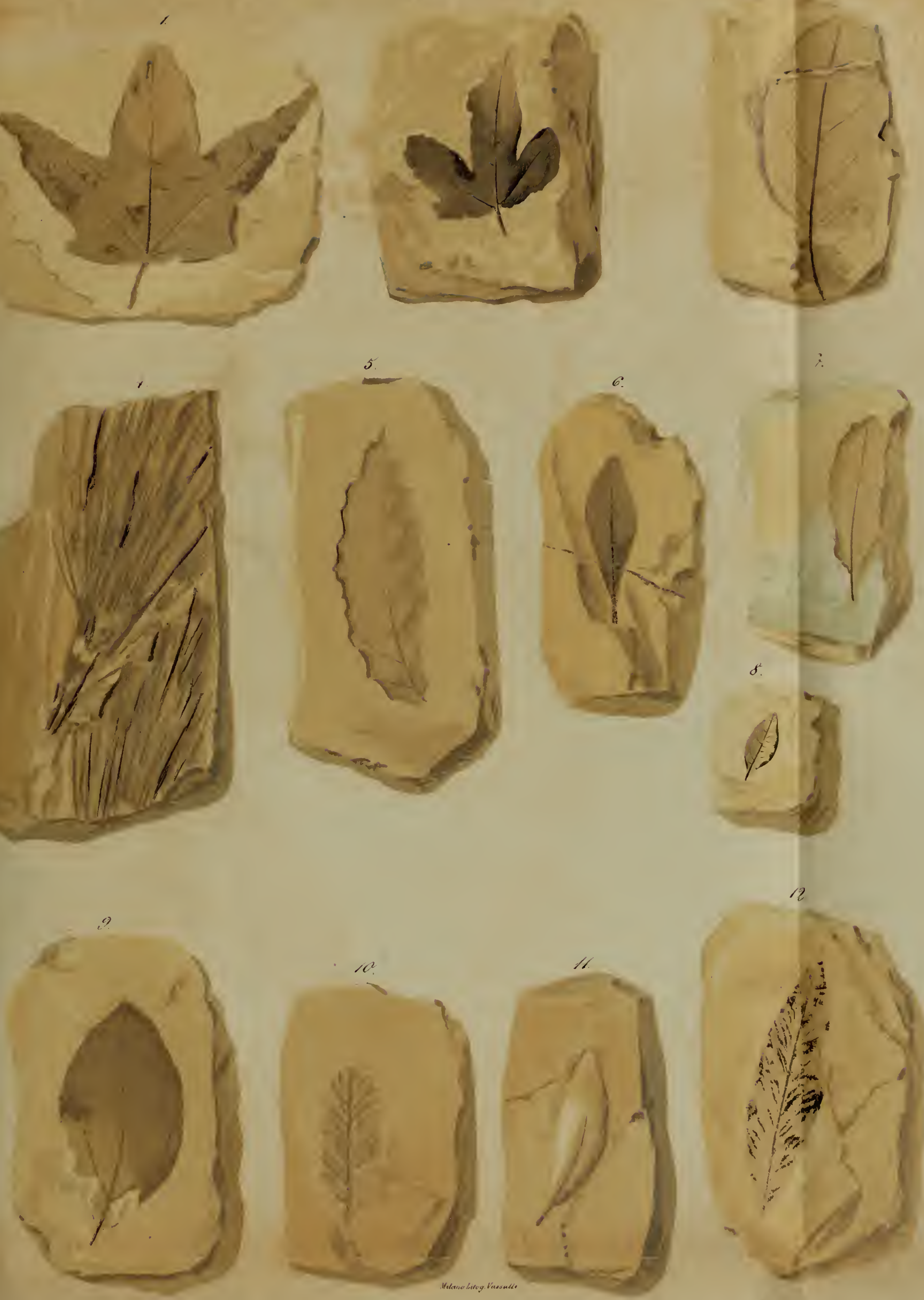

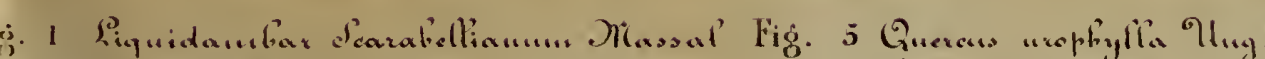

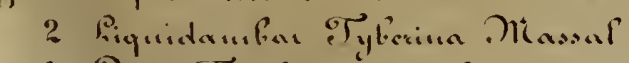

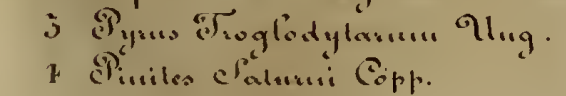

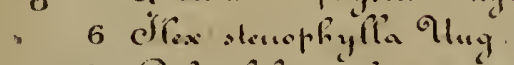

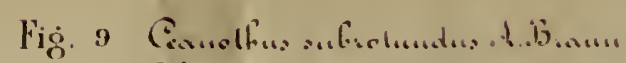

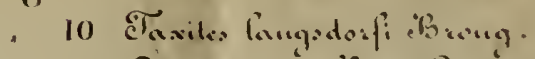

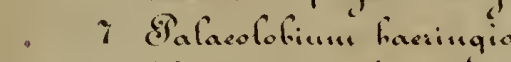

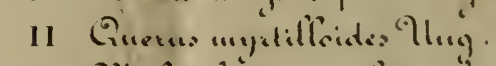

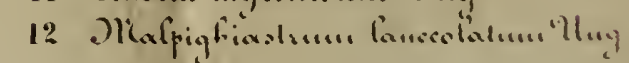


in
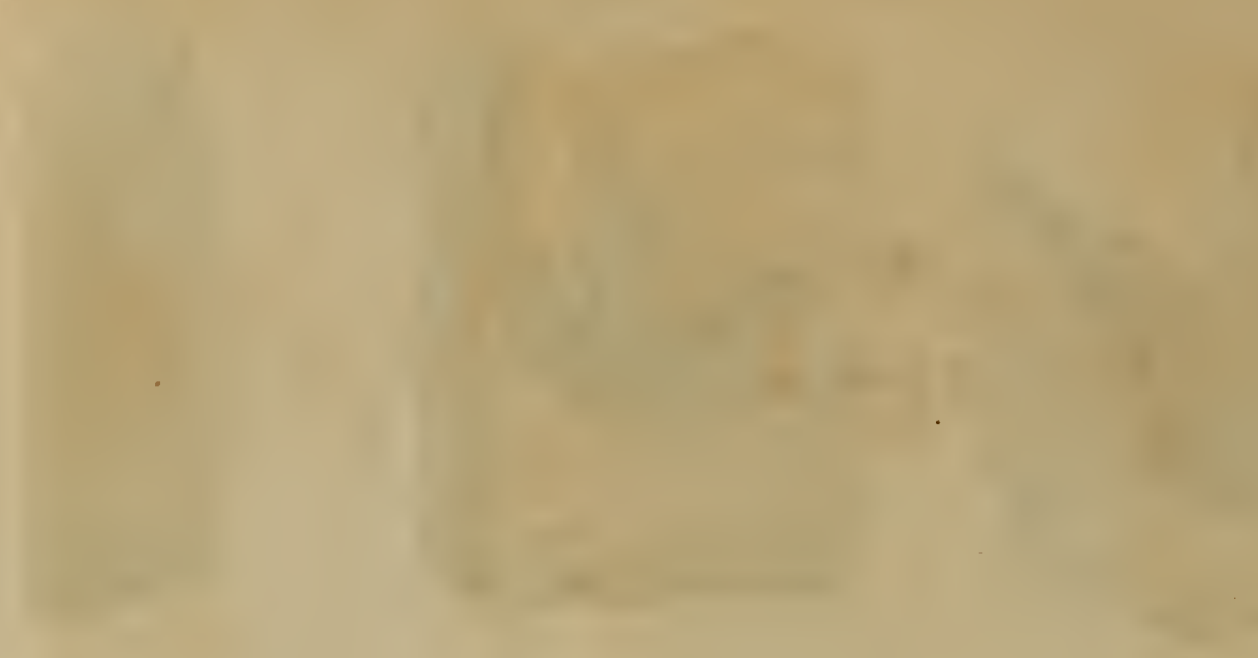

15
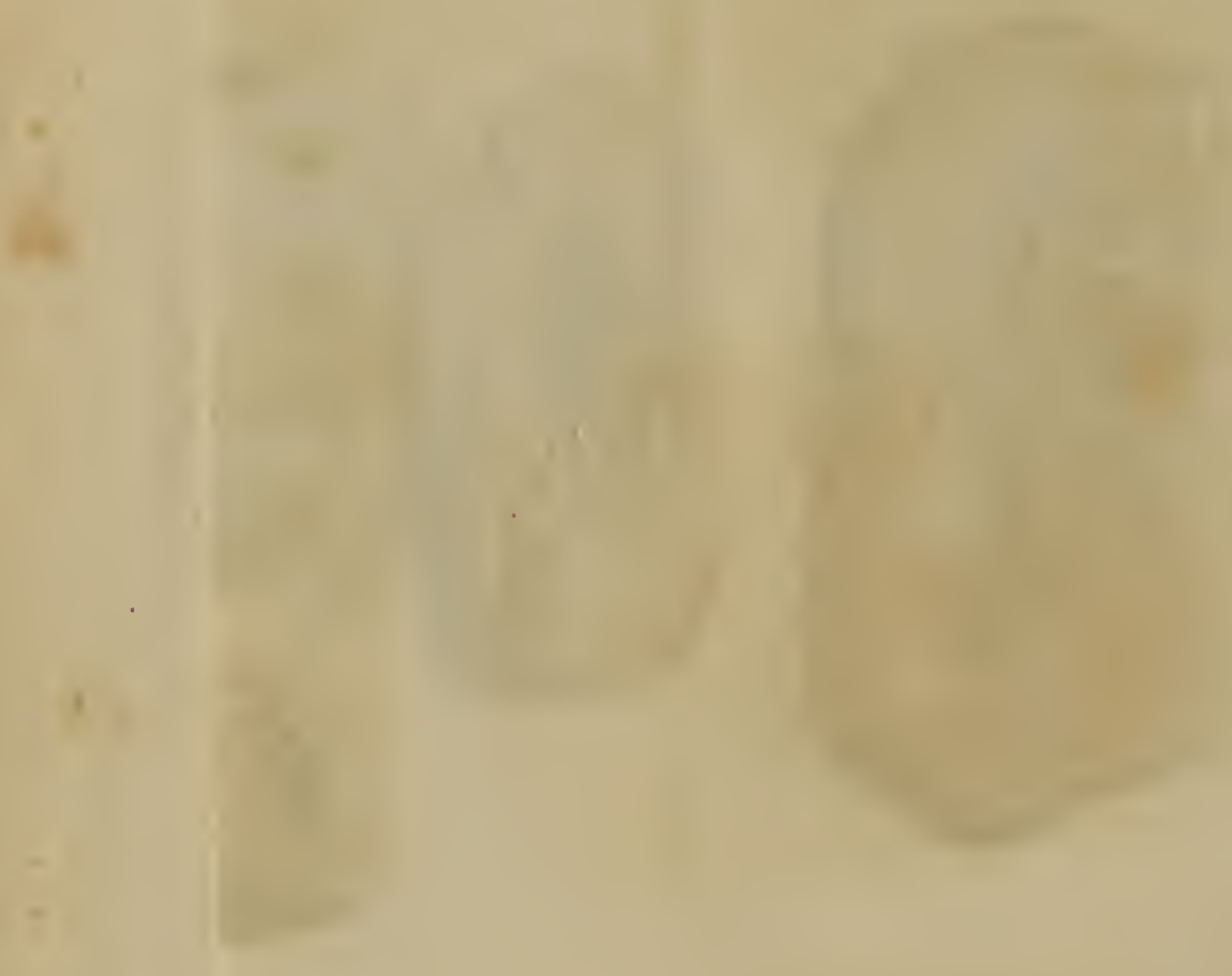

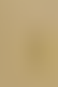

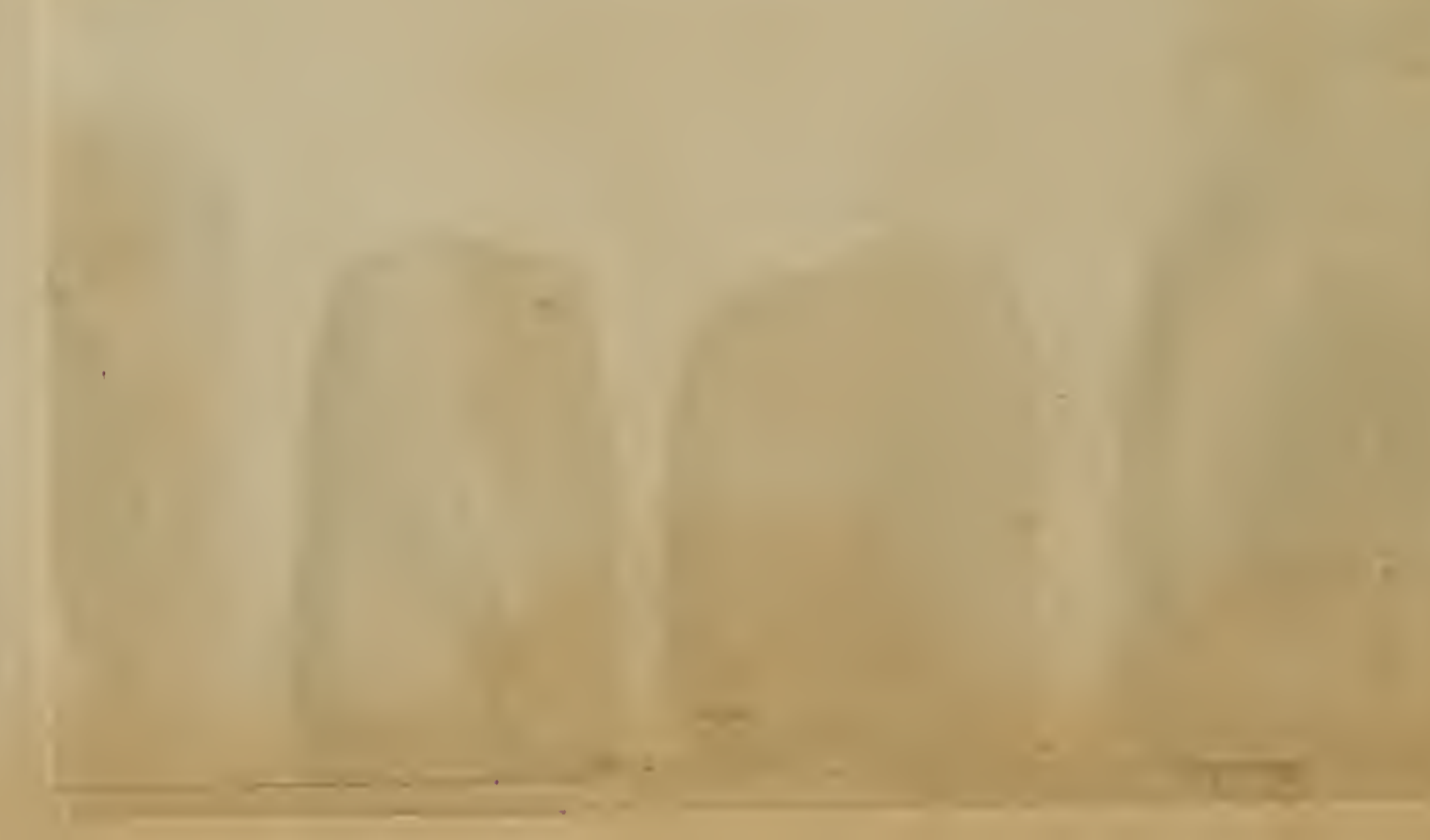



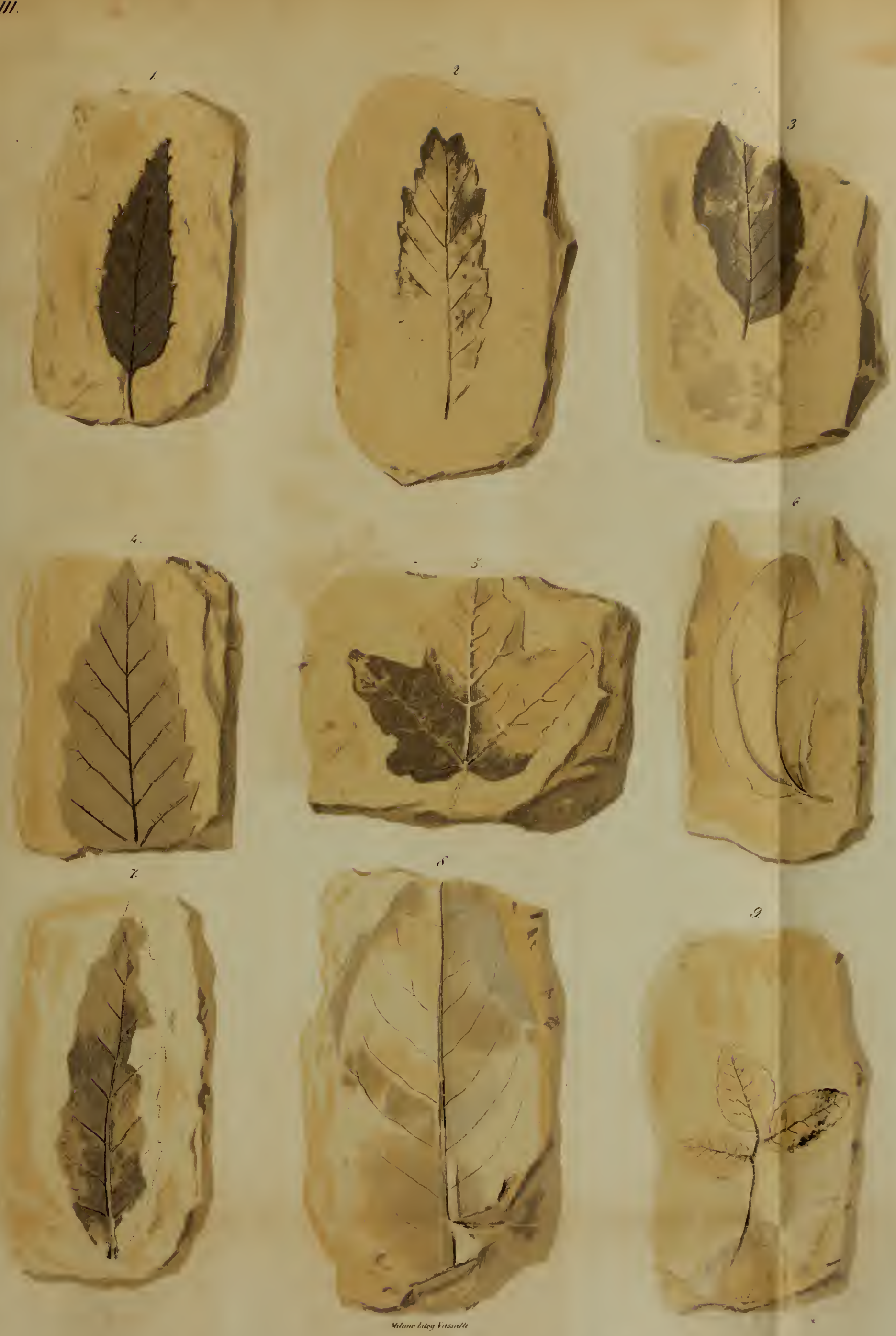

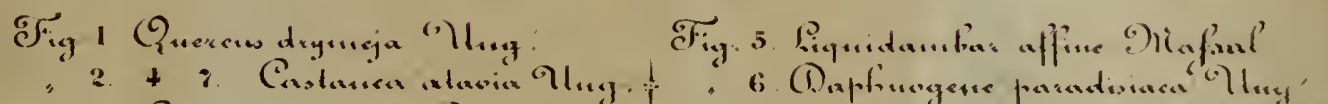

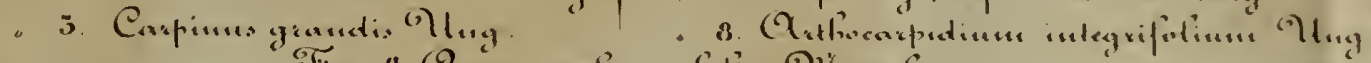

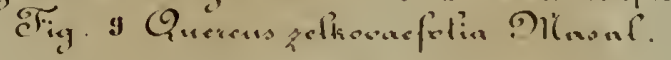




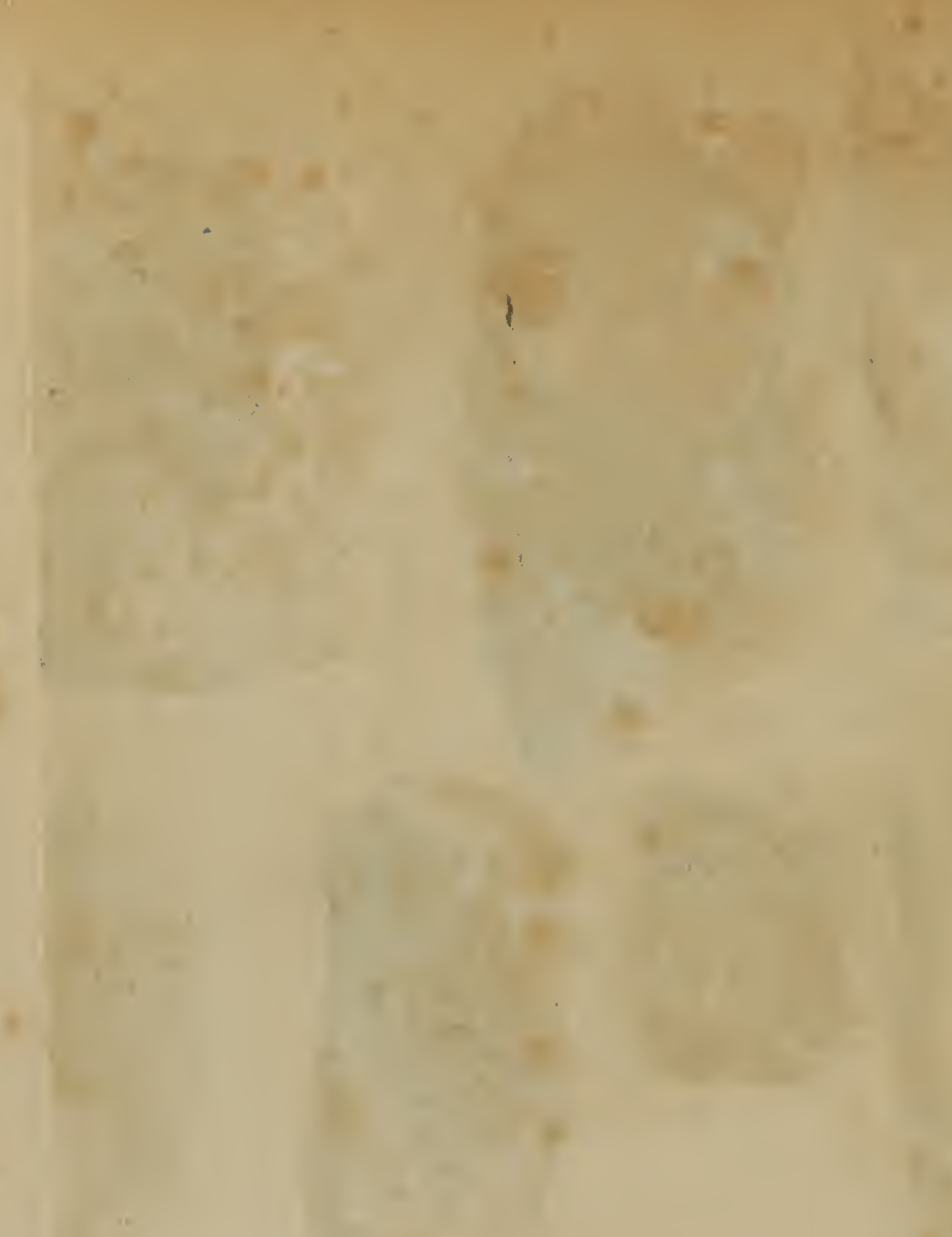

-
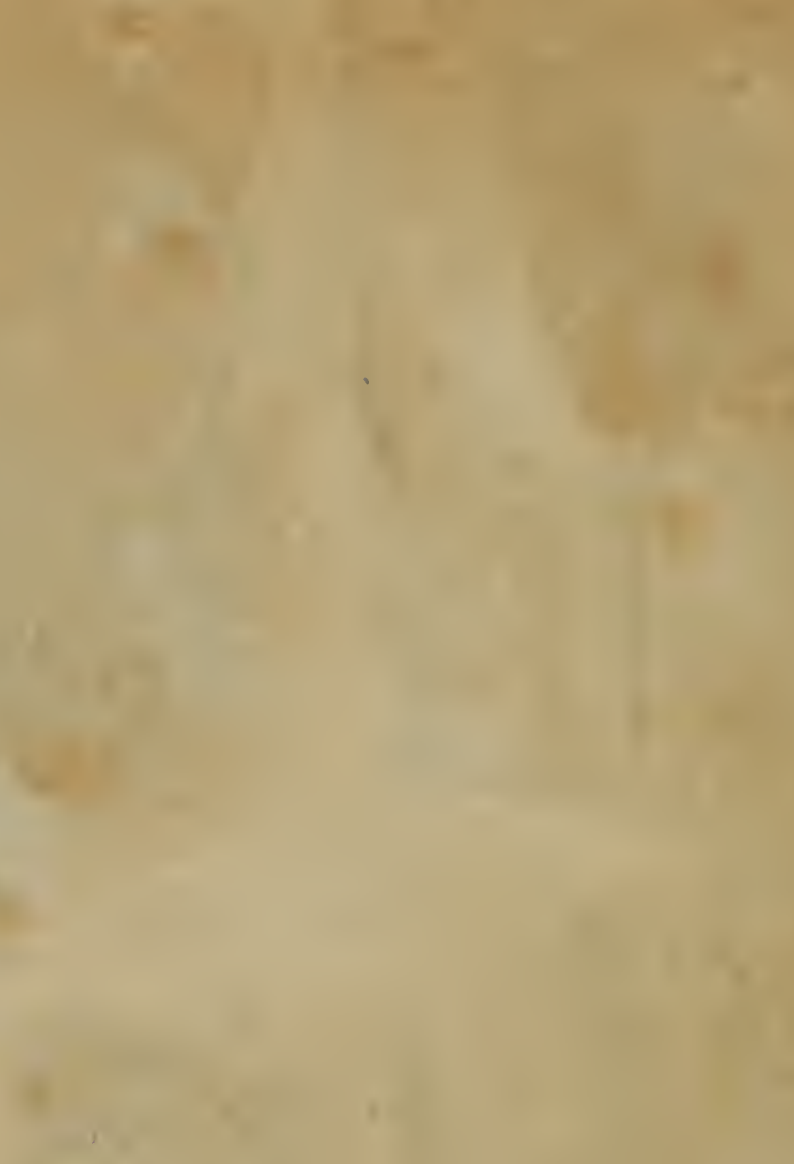


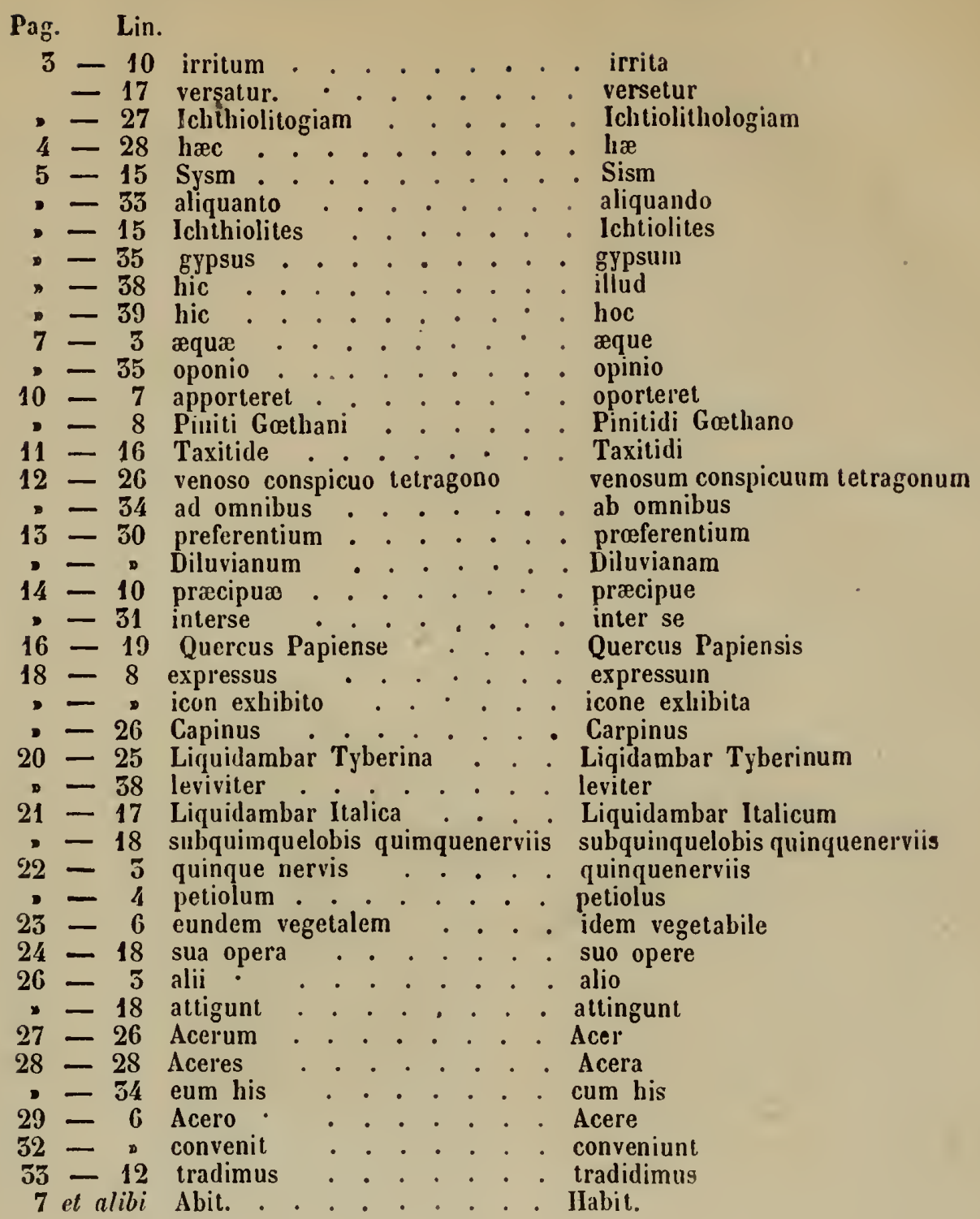



To avoid fine, this book should be returned on or before the date last stamped below

$10 \mathrm{~m}=10-47$ 

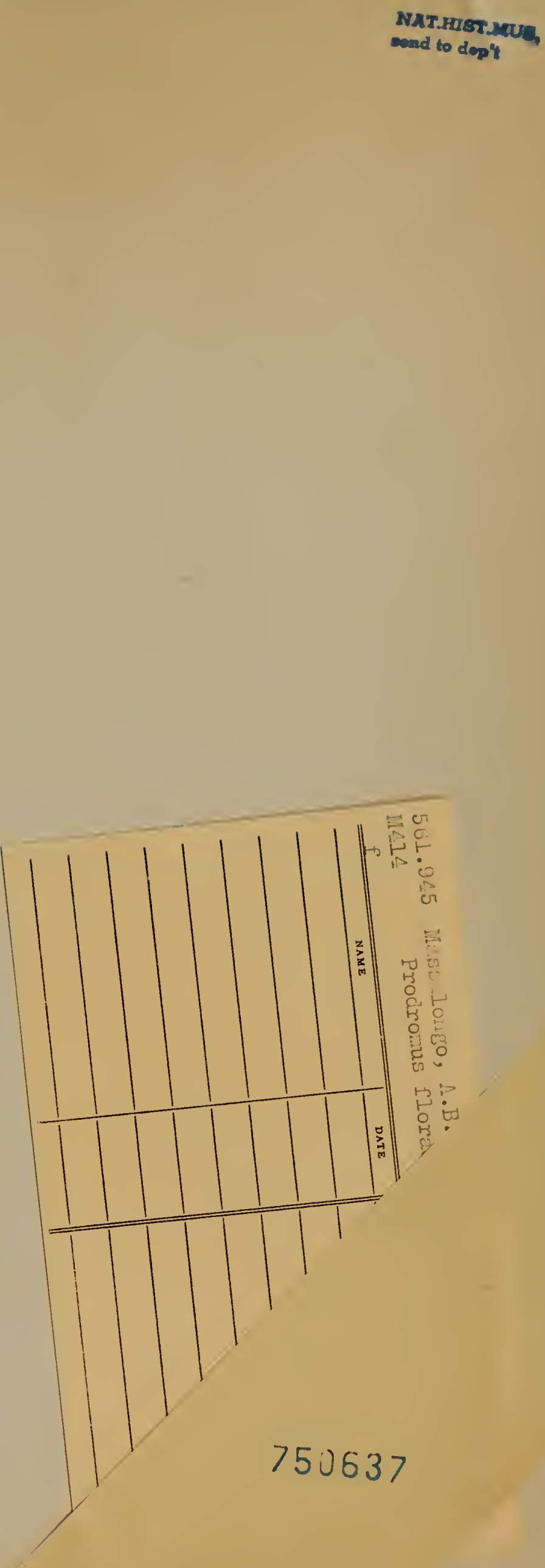
